\title{
The Role of Stationary Eddies in Shaping Midlatitude Storm Tracks
}

\author{
YOHAI KASPI \\ Weizmann Institute of Science, Rehovot, Israel \\ TAPIO SCHNEIDER \\ California Institute of Technology, Pasadena, California, and Swiss Federal Institute of Technology, Zurich, Switzerland
}

(Manuscript received 7 March 2012, in final form 28 February 2013)

\begin{abstract}
Transient and stationary eddies shape the extratropical climate through their transport of heat, moisture, and momentum. In the zonal mean, the transports by transient eddies dominate over those by stationary eddies, but this is not necessarily the case locally. In particular, in storm-track entrance and exit regions during winter, stationary eddies and their interactions with the mean flow dominate the atmospheric energy transport. Here it is shown that stationary eddies can shape storm tracks and control where they terminate by modifying local baroclinicity. Simulations with an idealized aquaplanet GCM show that zonally localized surface heating alone (e.g., ocean heat flux convergence) gives rise to storm tracks, which have a well-defined length scale that is similar to that of Earth's storm tracks. The storm tracks terminate downstream of the surface heating even in the absence of continents, at a distance controlled by the stationary Rossby wavelength scale. Stationary eddies play a dual role: within about half a Rossby wavelength downstream of the heating region, stationary eddy energy fluxes increase the baroclinicity and therefore contribute to energizing the storm track; farther downstream, enhanced poleward and upward energy transport by stationary eddies reduces the baroclinicity by reducing the meridional temperature gradients and enhancing the static stability. Transports both of sensible and latent heat (water vapor) play important roles in determining where storm tracks terminate.
\end{abstract}

\section{Introduction}

Fluxes of heat, momentum, and water vapor shape Earth's temperature, wind, and net precipitation distribution. In the extratropics in the zonal mean, these fluxes are dominated by transient eddies (Peixoto and Oort 1992). However, the zonal mean masks the fact that the transient eddies in the Northern Hemisphere are organized into zonally confined storm tracks-regions of enhanced transient eddy kinetic energy (Blackmon 1976) that owe their existence to the zonal asymmetries created by continents (Fig. 1a). (Transient eddies in the Southern Hemisphere are less zonally organized because the zonal asymmetries created by continents are weaker.) To understand the extratropical climate locally, it is therefore essential to understand how the organization of transient eddies into storm tracks is achieved. While it is

Corresponding author address: Yohai Kaspi, Weizmann Institute of Science, 234 Herzl St., Rehovot, Israel, 76100.

E-mail: yohai.kaspi@weizmann.ac.il clear that at least the wintertime storm tracks over the Pacific and Atlantic are generated by the enhanced baroclinicity and heat fluxes from the surface into the atmosphere in the vicinity of the western boundary currents (Figs. 1b,c), it is not clear what controls where the storm tracks terminate. The question of what controls the length scale of storm tracks is the subject of this paper.

Various hypotheses have been proposed to account for the length of storm tracks. Increased surface damping over land has been posited as a reason for reduced transient eddy kinetic energy (EKE) and the termination of storm tracks (Chang and Orlanski 1993; ZuritaGotor and Chang 2005; Mak and Deng 2007). Hoskins and Valdes (1990) argue that storm tracks may selfdestruct altogether if diabatic heating were not to enhance them in weakly baroclinic regions because enhanced transient energy fluxes by the storm tracks reduce baroclinicity. Alternatively, it has been suggested that storm tracks are maintained because of downstream development of eddies that form over the strongly baroclinic entrance regions, and the storm tracks then 

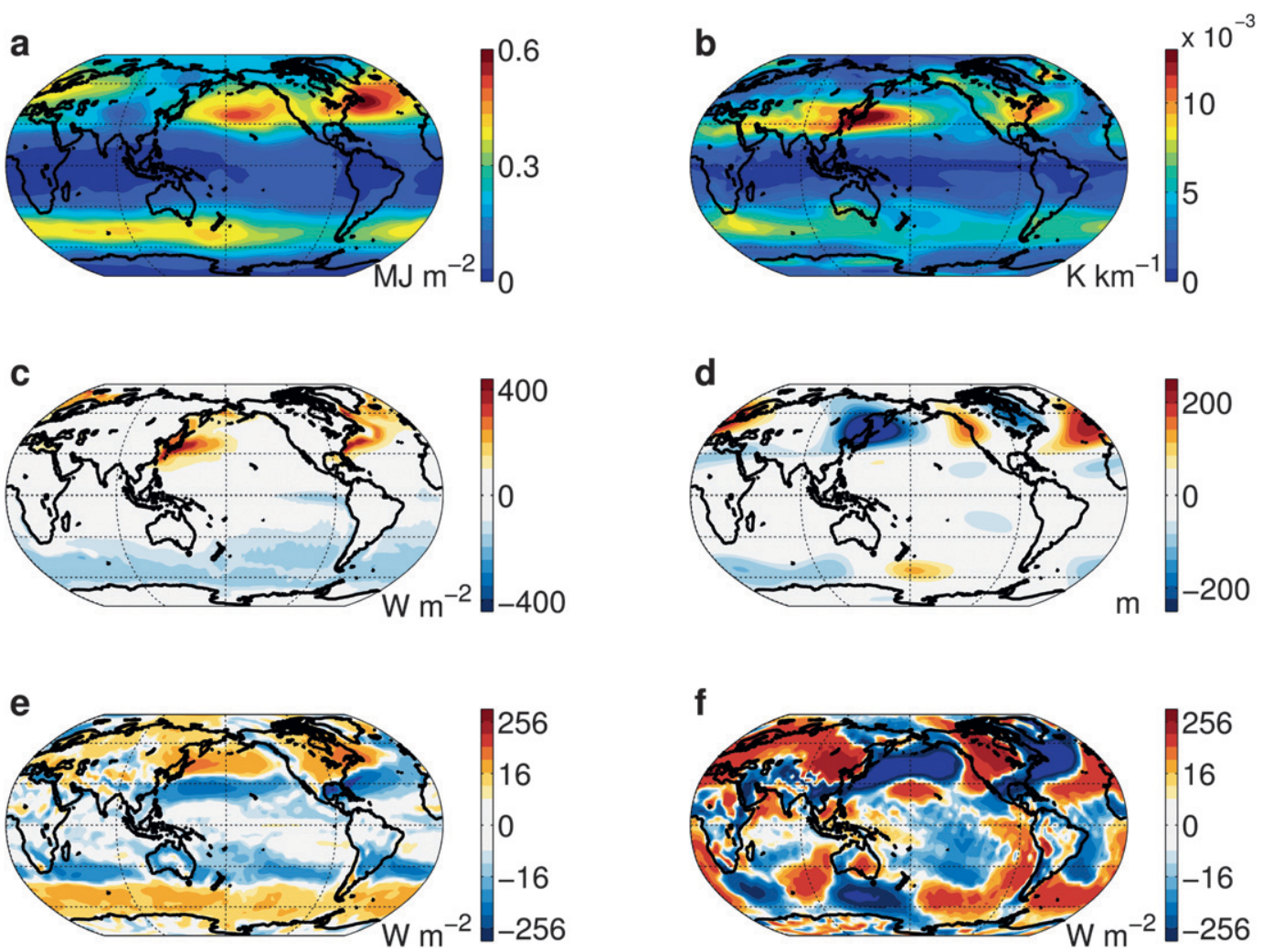

FIG. 1. National Centers for Environmental Prediction (NCEP) reanalysis fields averaged over Northern Hemisphere winter (December-February) and over the years 1970-2009. (a) Vertically integrated kinetic energy of 3-10-day bandpass-filtered transient eddies. Eddy kinetic energy is defined as $1 / 2 \int\left(u^{2}+v^{2}\right) d p / g$. (b) Absolute value of meridional temperature gradient vertically averaged in the troposphere. (c) Total upward energy flux from the surface into the atmosphere (sum of the latent heat flux, sensible heat flux, and net upward radiative energy flux). (d) 300-hPa geopotential anomaly. (e) Vertically integrated moist static energy flux convergence by transient eddies $\left\{-\nabla \cdot\left(\overline{v^{\prime} m^{\prime}}\right)\right\}$. (f) Vertically integrated moist static energy flux convergence by stationary eddies $\left\{-\nabla \cdot\left(\bar{v}^{\dagger} \bar{m}^{\dagger}\right)\right.$; for definitions, see section 3 \}. The vertically integrated fields are integrated between 300 and $1000 \mathrm{hPa}$. The color scales for (e),(f) are logarithmic, with factors of 2 separating contour levels. Here and in subsequent figures, latitudinal and longitudinal grid lines are $30^{\circ}$ and $90^{\circ}$ apart, respectively.

terminate downstream because of dissipation or barotropic decay of the eddies (Simmons and Hoskins 1980; Orlanski and Katzfey 1991; Chang 1993; Chang and Orlanski 1993; Orlanski 1998; Frisius et al. 1998).

An alternative hypothesis is that orographic stationary eddies play a role in shaping storm tracks of transient eddies. Several studies have indicated that there are interactions between stationary and transient eddies. On the one hand, it has been shown that the dynamic heating associated with transient eddies and their zonal organization into storm tracks is an important driver of stationary eddies (e.g., Held et al. 2002). On the other hand, GCM simulations have shown that if orography and with it the stationary eddies it generates are reduced, the Northern Hemisphere storm tracks become more zonally symmetric even in the presence of landocean contrast (Broccoli and Manabe 1992). Transient eddies in storm tracks thus drive stationary eddies, and stationary eddies (Fig. 1d) in turn shape storm tracks (Branstator 1995; Peng and Whitaker 1999; Chang et al. 2002; Inatsu et al. 2003). Stationary eddies may shape storm tracks, for example, through modifications of the baroclinicity (Lee 1995; Inatsu et al. 2003) or of the barotropic background flow (Manabe and Terpstra 1974; Lee 1995; Harnik and Chang 2004; Son et al. 2009; Park et al. 2010; Brayshaw et al. 2009; Sauliére et al. 2012).

How stationary eddies may lead to the termination of storm tracks through baroclinic processes has received less attention in the recent literature, possibly because in the zonal-mean transient eddies dominate the poleward and upward transport of sensible and latent heat. Locally, however, energy fluxes associated with stationary eddies can be significant (Oort and Peixóto 1983; Lau 1979a,b) and, in fact, they dominate those associated with transient eddies (Figs. 1e,f). The stationary eddy fluxes include components owing to eddy-mean flow 
interactions, namely, owing to the advection of the zonalmean moist static energy (MSE) by stationary eddies and to the advection of the stationary-eddy MSE by the zonal-mean flow. (The relative contributions of the various parts of the MSE are discussed in greater detail in section 3.) The energy flux divergences are locally dominated by stationary eddies. It is plausible, then, that baroclinic modifications of the background flow by stationary eddies exert a substantial influence on stormtrack organization.

In Kaspi and Schneider (2011a), we showed that storm tracks have a finite length and self-destruct downstream of region of enhanced baroclinicity because of enhanced poleward heat transport by stationary eddies. Here we focus on the spatial distribution of the transient and stationary eddies to elucidate the mechanisms maintaining a storm track and controlling its length. We use simulations with an idealized aquaplanet GCM to study systematically how transient and stationary eddies interact and shape storm tracks. In the GCM, we generate storm tracks by prescribing a zonally localized surface heating. Similar to those in Earth's atmosphere, these storm tracks have a well-defined extent, whose dynamical origin we investigate by varying the planetary rotation rate. We use a GCM with a representation of the atmospheric hydrologic cycle to capture moist processes that are suspected to be important for storm-track dynamics. For example, the generation of eddy energy through the release of latent heat in phase changes of water in warm sectors of cyclones can energize transient eddies and can contribute to the maintenance of storm tracks (Hoskins and Valdes 1990; Chang 2001; Chang et al. 2002; Inatsu et al. 2003). At the same time, the release of latent heat can stabilize the thermal stratification, and meridional latent heat transport can reduce meridional temperature gradients, thus reducing baroclinicity and potentially damping transient eddies (e.g., Lee and Held 1993; Schneider and O'Gorman 2008). The relative importance of these competing roles of latent heat release-energizing eddies and reducing baroclinicity-is insufficiently understood (Schneider et al. 2010). Both may play a role in shaping storm tracks.

The model is described in section 2. In section 3, the stationary and transient eddies generated in response to a localized surface heating are analyzed and are shown to resemble those seen in Earth's atmosphere. Section 4 presents simulations with different planetary rotation rates, which allow us to study storm tracks whose length varies from a fraction to the full length of an extratropical latitude circle. We find two key stationary-eddy mechanisms that control where storm tracks terminate. In the first, stationary eddies increase meridional temperature gradients for about half a Rossby wavelength
TABLE 1. Rotation rates, resolutions, and resulting energy-containing wavenumbers of the simulations.

\begin{tabular}{ccc}
\hline $\begin{array}{c}\text { Rotation rate } \\
\left.\text { (multiples of } \Omega_{e}\right)\end{array}$ & Resolution & $\begin{array}{c}\text { Energy-containing } \\
\text { wavenumber }\end{array}$ \\
\hline 12 & T127 & 42.9 \\
8 & T127 & 32.9 \\
6 & T127 & 26.1 \\
4 & T85 & 19.6 \\
3 & $\mathrm{~T} 85$ & 15.9 \\
2 & $\mathrm{~T} 85$ & 12.2 \\
$4 / 3$ & $\mathrm{~T} 85$ & 9.7 \\
1 & $\mathrm{~T} 85$ & 8.5 \\
$2 / 3$ & $\mathrm{~T} 42$ & 6.8 \\
$1 / 2$ & $\mathrm{~T} 42$ & 6.1 \\
$1 / 4$ & $\mathrm{~T} 42$ & 4.6 \\
\hline
\end{tabular}

downstream, mainly because of zonal energy fluxes by stationary eddies. In the second, stationary eddies reduce baroclinicity farther downstream because they reduce meridional temperature gradients and enhance the static stability through their poleward and upward transport particularly of latent heat. These mechanisms are analyzed in section 5 .

\section{Idealized GCM with zonal asymmetries}

\section{a. Model}

We use an idealized GCM with a simple representation of moisture. The model is based on the GFDL Flexible Modeling System (GFDL 2004). It is a sphericalcoordinate primitive equation model of an ideal-gas atmosphere, which is similar to that used by O'Gorman and Schneider (2008b) and Frierson et al. (2006). For our reference simulation, we use a horizontal resolution of T42 and 30 vertical sigma levels. For simulations with higher planetary rotation rates, we use the higher horizontal resolutions of T85 and T127, to resolve the smaller eddies (see Table 1). To damp small scales, scale-selective eighth-order hyperdiffusion is included in the vorticity, divergence, and temperature equations.

The lower model boundary is a uniform slab ocean with no dynamics, but with local energy balance. The surface temperature is not prescribed, unlike in many previous studies of storm tracks (e.g., Inatsu et al. 2002, 2003; Brayshaw et al. 2008, 2009, 2011; Sauliére et al. 2012). It changes in response to changing surface fluxes of radiative energy, sensible heat, and latent heat. A planetary boundary layer scheme with Monin-Obukhov surface fluxes, which depend on the stability of the boundary layer, links atmospheric dynamics to surface fluxes of momentum, latent heat, and sensible heat. Radiative transfer is represented by a two-stream gray radiation scheme with longwave and shortwave optical depths that only depend on latitude and pressure, and 
a top-of-the-atmosphere insolation, which is approximately equal to Earth's annual-mean insolation. Moist convection is represented by a slightly modified version (O'Gorman and Schneider 2008b) of the quasi-equilibrium convection scheme of Frierson (2007). It relaxes temperature profiles toward a moist-adiabatic profile, and water vapor profiles toward a profile with fixed relative humidity, whenever a parcel lifted from the lowest model level is convectively unstable. Large-scale condensation removes water vapor from the atmosphere when the specific humidity on the grid scale exceeds the saturation specific humidity. The model neglects clouds, aerosols, sea ice, and seasonal effects. Using such an idealized model (while producing an Earth-like zonalmean climate) allows the specific mechanisms driving the dynamics to be isolated and gives us the computational ability to do systematic experiments over a broad range of parameters.

\section{b. Simulations}

To study storm-track length in an aquaplanet idealized GCM, we must introduce some zonal asymmetries. Such asymmetries can be introduced in several ways, for example, by using orography (e.g., Son et al. 2009; Brayshaw et al. 2009) or by thermal forcing (e.g., Peng and Whitaker 1999; Kushnir et al. 2002; Inatsu et al. 2003; Chang 2009; Brayshaw et al. 2011). In this study, we do so by applying a localized heat flux convergence (a " $Q$ flux") at the model's bottom boundary, a slab ocean of 1-m depth. This creates a localized heat source, representing a warm area in the ocean such as the Gulf Stream or Kuroshio western boundary currents. We apply the localized surface heating over a triangular area in the Northern Hemisphere between latitudes $25^{\circ}$ and $50^{\circ} \mathrm{N}$ (see Fig. 2), crudely representing the shape of the western oceanic boundaries (both North America and Asia have an eastern boundary with a coast line extending in the southwest-northeast direction). The particular shape, size, and magnitude of the local heat source do not affect our results qualitatively. To allow comparison with a control case, we add in the Southern Hemisphere the same ocean heat flux convergence but spread over all longitudes in a zonally symmetric way. This allows us to treat the Southern Hemisphere as a control case with no zonal asymmetry and with the same zonal-mean thermal driving.

The magnitude of the localized surface heating is chosen so that the enhanced temperature gradients near the forcing region are similar to those observed in the entrance region of the Northern Hemisphere storm tracks in winter (cf. Figs. $2 b$ and $1 b$ ). We achieve temperature gradients with peak values near $1.3 \times$ $10^{-3} \mathrm{~K} \mathrm{~km}^{-1}$ with a $Q$ flux of $850 \mathrm{~W} \mathrm{~m}^{-2}$. We will refer to
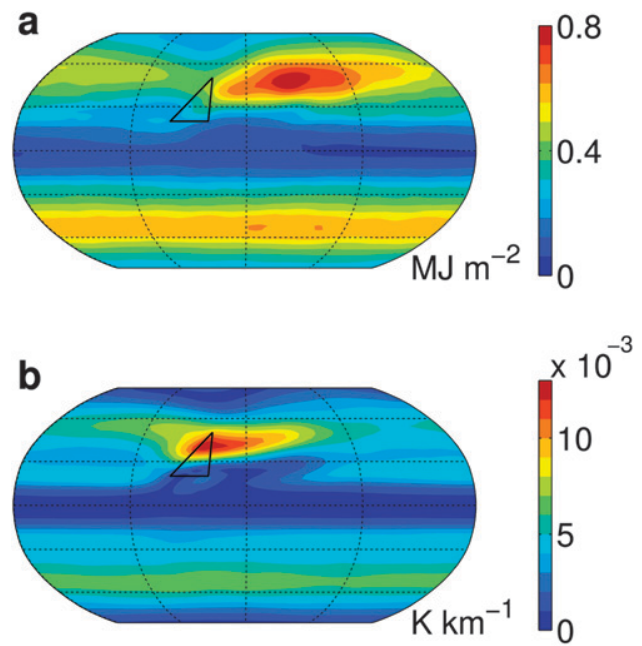

c

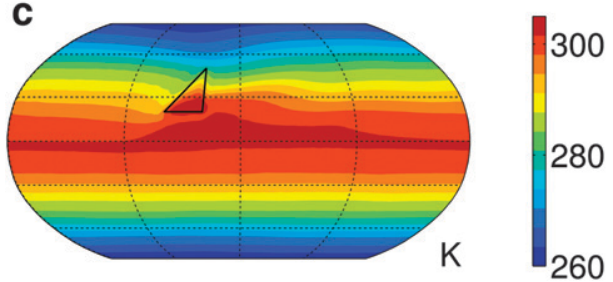

FIG. 2. Response to a localized surface heating in the reference simulation. (a) Vertically integrated tropospheric eddy kinetic energy. (b) Vertically averaged absolute value of meridional temperature gradient. (c) Surface air temperature. The triangle indicates the region where the surface heating $\left(850 \mathrm{~W} \mathrm{~m}^{-2}\right)$ is applied. The magnitude of the surface heating is chosen so that the temperature gradients in (b) roughly match observations (Fig. 1b). The vertically integrated fields are integrated between $\sigma=0.3$ and the surface.

this case as our reference simulation, which provides us with the reference climate that we study here. This heat flux is larger than the observed flux over the western oceanic boundaries (Fig. 1c) because the simplicity of the model (e.g., the lack of a land-ocean contrast) requires an enhanced heat flux to reproduce atmospheric characteristics such as realistic meridional temperature gradients or atmospheric heat fluxes. Simulations with different $Q$ fluxes show that its magnitude is not essential for the results on which we focus here. In our reference simulation, the localized $Q$ flux results in surface air temperature increases of about $7 \mathrm{~K}$ compared to similar latitudes away from the heating region (Fig. 2c). Despite the enhanced heat flux in the model, this is less than the anomalous surface air temperature contrast across western oceanic boundaries (Seager et al. 2002; Kaspi and Schneider 2011b).

To allow a wide variation of length scales of both the eddies and the storm tracks we vary the rotation rate of 
the planet. We use simulations with rotation rates between $1 / 4$ and 12 times that of Earth. A summary of the experiments, the model resolutions, and the resulting energy-containing wavenumbers (defined in section 4) is given in Table 1. All experiments are spun up for at least 2000 days to a statistically steady state. The time-mean results presented here are averaged for at least a subsequent 700 days.

\section{c. Response to a localized heat source}

In the reference simulation, the localized surface heating results in a localized downstream (to the east) increase in transient EKE in a well-defined storm track (Fig. 2a). Such storm-track generation was seen in previous studies with prescribed sea surface temperatures (Inatsu et al. 2002, 2003). EKE has a peak downstream of the perturbation region and then decays farther downstream to values lower than in the control Southern Hemisphere. Thus, the existence of a region of localized surface heating creates not only a region of high EKE immediately downstream, because of enhanced baroclinicity and diabatic heating, but also a region of damped EKE farther downstream, both compared with the Southern Hemisphere and with a case with no additional (zonally asymmetric or symmetric) heating (Kaspi and Schneider 2011a). The surface air temperature is increased in the heating region and immediately downstream of it owing to advection by the mean flow (Fig. 2c). In addition, surface temperatures are lowered immediately upstream of the heating region. This is an upstream response set by stationary waves, which generate a negative temperature anomaly within a Rossby wave plume (Kaspi and Schneider 2011b). Furthermore, the localized surface heating leads to an increase in the meridional temperature gradient poleward of the heating region and immediately downstream of it (Fig. 2b).

Comparing Figs. $2 \mathrm{a}$ and $2 \mathrm{~b}$ to Figs. $1 \mathrm{a}$ and $1 \mathrm{~b}$ shows that EKE and meridional temperature gradients in our reference simulation match the reanalysis data well. The storm-track EKE peaks downstream and poleward of the source region and is elevated over a similar distance downstream as on Earth, although the idealized model has no continents or topography.

\section{Interaction between stationary and transient eddies}

The response of the system to the localized surface heating consists of a locally enhanced transient EKE (the storm track) and the formation of stationary eddies. To understand the relative contribution of transient and stationary eddies to the energy budget, we compare simulations with a localized zonally asymmetric surface heating with simulations without zonal asymmetries at

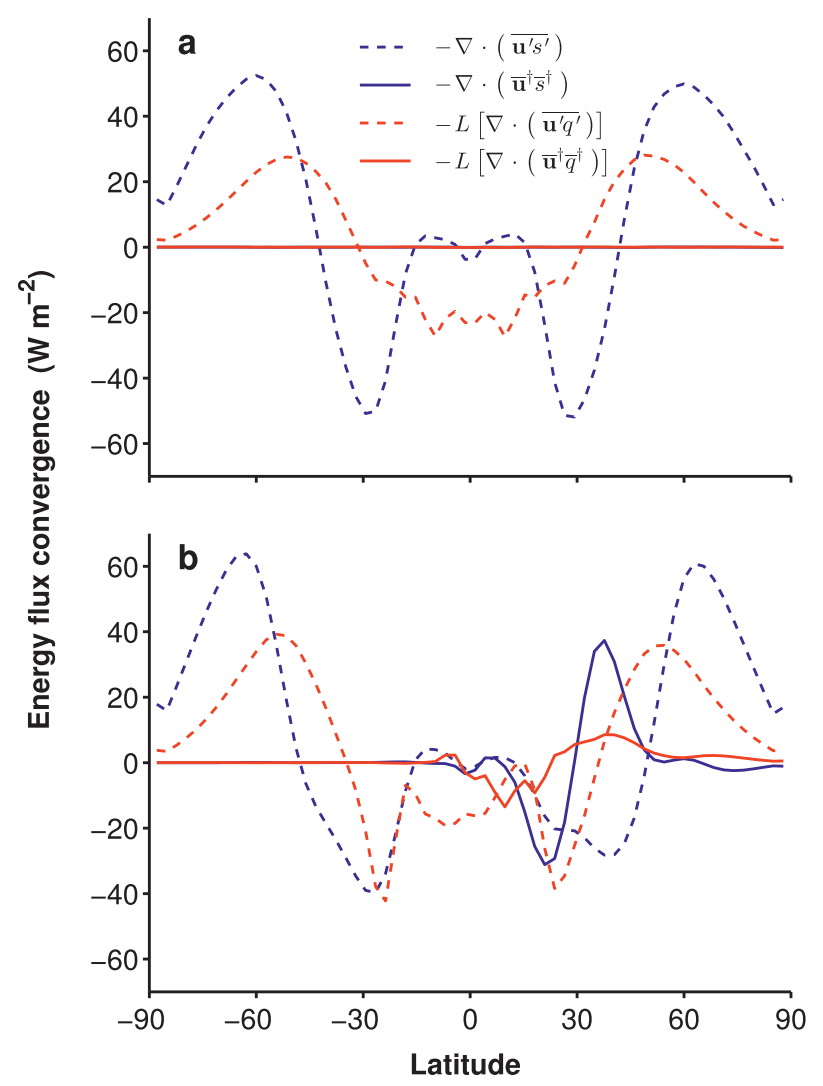

FIG. 3. Vertically integrated and zonally averaged transient (dashed) and stationary eddy (solid) contributions to the energy flux convergence from DSE (blue) and LE (red). (a) Simulation with no added surface heating. (b) Reference simulation with added localized surface heating in the Northern Hemisphere and with zonally symmetric surface heating in the Southern Hemisphere (Fig. 2). All fields are vertically integrated throughout the entire atmosphere.

the boundaries. Without zonal asymmetries, the stationary eddy contribution vanishes as expected (Fig. 3a). The transient eddy fluxes of dry static energy (DSE) $s=$ $c_{p} T+g z$ and latent energy (LE) $L q$ both diverge in the tropics and subtropics and converge in the extratropics. For DSE and LE we use standard definitions (Peixoto and Oort 1992), with the specific heat of dry air $c_{p}=$ $1004 \mathrm{~J} \mathrm{~kg}^{-1} \mathrm{~K}^{-1}$ and the latent heat of vaporization $L=$ $2.5 \times 10^{6} \mathrm{~J} \mathrm{~kg}^{-1}$, consistent with the thermodynamics of our GCM. Thus, in the zonally symmetric case, the poleward energy flux owing to transient eddies reduces the pole-to-equator temperature gradients. ${ }^{1}$ However, with zonal asymmetries at the lower boundary, the picture becomes more complicated: stationary eddies contribute significantly to the energy flux convergence (Fig. 3b).

\footnotetext{
${ }^{1}$ When we refer to the energy flux, we refer to the static component of the energy flux.
} 
To define stationary and transient eddy fluxes locally, we split fields into deviations from the time and zonal means. We denote by $(\cdot)^{\prime}$ the deviation from the time mean $\overline{(\cdot)}$, so that $(\cdot)=\overline{(\cdot)}+(\cdot)^{\prime}$, and by $(\cdot)^{*}$ the deviation from the zonal mean $[\cdot]$, so that $(\cdot)=[\cdot]+(\cdot)^{*}$. Then, for example, the time mean meridional DSE flux can be split so that

$$
\overline{v s}=\overline{v^{\prime} s^{\prime}}+\bar{v}^{*} \bar{s}^{*}+[\bar{v}] \bar{s}^{*}+\bar{v}^{*}[\bar{s}]+[\bar{v}][\bar{s}] .
$$

Zonally averaged, the third and fourth terms on the right-hand side vanish, leaving just the contribution from the transient eddies, the stationary eddies, and the mean meridional circulation (e.g., Peixoto and Oort 1992),

$$
[\overline{v s}]=[\bar{v}][\bar{s}]+\left[\bar{v}^{*} \bar{s}^{*}\right]+\left[\overline{v^{\prime} s^{\prime}}\right]
$$

Locally, however, the cross terms in (1), representing stationary eddy-mean flow interactions, are significant, and the stationary eddy response locally includes the second, third, and fourth term in (1). We define the total stationary eddy response because of the existence of zonal asymmetries as

$$
\bar{v}^{\dagger} \bar{s}^{\dagger} \equiv \bar{v} \bar{s}-[\bar{v}][\bar{s}]=[\bar{v}] \bar{s}^{*}+\bar{v}^{*}[\bar{s}]+\bar{v}^{*} \bar{s}^{*},
$$

which includes the interaction with the mean flow. An analogous analysis applies to the zonal and vertical components of the energy flux.

To analyze how the stationary and transient eddy energy flux terms affect temperature gradients and baroclinicity locally, it is useful to decompose the DSE budget into the terms in (1) so that

$$
\begin{aligned}
\frac{\partial \bar{s}}{\partial t}= & -\nabla \cdot\left(\overline{\mathbf{u}^{\prime} s^{\prime}}\right)-\nabla \cdot\left(\overline{\mathbf{u}}^{*} \bar{s}^{*}\right)-\nabla \cdot\left([\overline{\mathbf{u}}] \bar{s}^{*}\right) \\
& -\nabla \cdot\left(\overline{\mathbf{u}}^{*}[\bar{s}]\right)-\nabla \cdot([\overline{\mathbf{u}}][\bar{s}])+Q,
\end{aligned}
$$

where $Q$ is the diabatic heating. The time derivative vanishes in a statistically steady state. On the right-hand side, there is the flux convergence of the transient eddies (first term), the flux convergence of the stationary eddies (second term), advection of the stationary eddy DSE by the zonal-mean flow (third term), advection of the zonal-mean DSE by the stationary eddies (fourth term), and advection of the zonal-mean DSE by the zonalmean flow (fifth term). In the zonal mean $\left(\left[\overline{\mathbf{u}}^{\dagger} \bar{s}^{\dagger}\right]=\left[\overline{\mathbf{u}}^{*} \bar{s}^{*}\right]\right)$, the contribution from the stationary eddies in the Northern Hemisphere (where the localized surface heating was added) is of the same magnitude as the contribution of the transients, both for the DSE and LE flux convergence (Fig. 3b), as is the case in Earth's atmosphere (Peixoto and Oort 1992). In the Southern Hemisphere (where the added surface heating is zonally symmetric), the stationary eddy contribution essentially vanishes. The Southern Hemisphere transient eddy contribution in the reference simulation (Fig. 3b) is not identical to that in the simulation without added surface heating (Fig. 3a) because the additional, zonally symmetric, surface heating broadens the flux convergence poleward.

Locally, however, the contribution of the stationary eddies is much larger than that of the transients. Figure 4 shows the vertically integrated transient eddy (top) and stationary eddy (bottom) DSE (left) and LE (right) flux convergences. The stationary eddy DSE flux convergence is locally the dominant term in the Northern Hemisphere, particularly near the region of the localized surface heating (Fig. 4c). Upstream of the localized heating, there is strong divergence, indicating dynamic cooling. The most significant feature is that downstream of the localized heating, there is a strong front between convergence to the south and divergence to the north of the storm track (also in Fig. 1f). This is caused primarily by the zonal advection of DSE by the mean flow, over a length scale controlled by stationary eddies (see discussion below). This process opposes the tendency of the transient eddies to reduce pole-to-equator temperature gradients (Fig. 4a). Therefore, one reason storm tracks do not self-destruct immediately downstream of their entrance regions (Hoskins and Valdes 1990) is that stationary eddies (including their interaction with the mean flow) act against the transients to maintain baroclinicity. Farther downstream, the effect of stationary eddies on the pole-to-equator temperature gradients is reversed: weaker convergence or divergence to the south and convergence to the north of the storm track indicate that stationary eddies reduce baroclinicity there. In our reference simulation, this occurs about $90^{\circ}$ east of the localized heating, and it contributes to the self-destruction of EKE downstream of the storm track (Kaspi and Schneider 2011a).

The most significant feature of the stationary LE flux (Fig. 4d) is the strong convergence in midlatitudes, on the equatorward flank of the storm track, and the strong divergence over and equatorward of the surface heating region. Thus, there is an LE flux from the tropics equatorward of the heating region into midlatitudes. This is similar to the "atmospheric rivers" seen in observations (e.g., Newell et al. 1992; Zhu and Newell 1998; Newman et al. 2012), which carry out much of the poleward moisture transport in Earth's atmosphere. This moisture transport occurs in filaments extending off extratropical cyclones toward the equator; hence, the atmospheric 

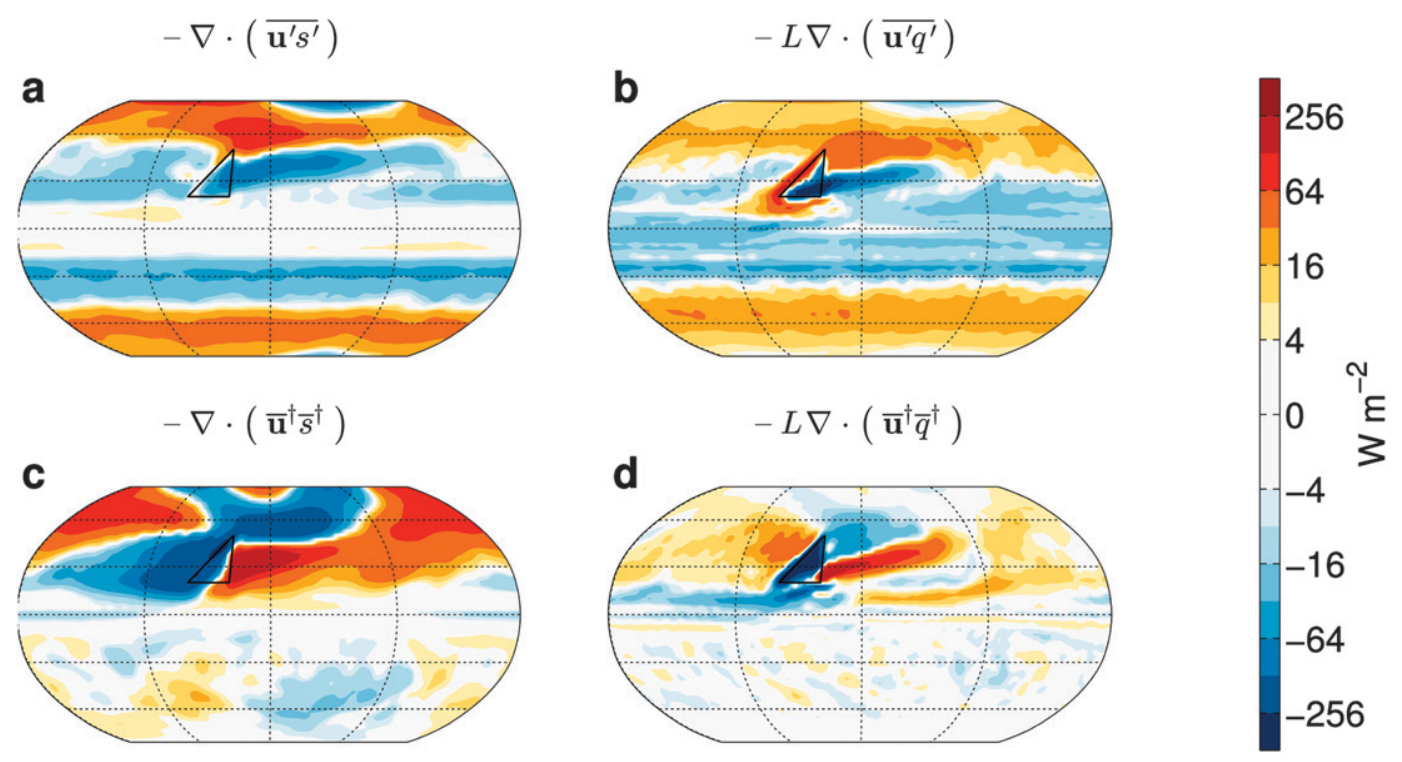

FIG. 4. Vertically integrated convergence of DSE and LE fluxes. (a) Transient eddy DSE flux convergence. (b) Transient eddy LE flux convergence. (c) Stationary eddy DSE flux convergence. (d) Stationary eddy LE flux convergence. These are the same fields as in Fig. 3, but are shown only temporally (not zonally) averaged. The color scale is logarithmic, with factors of 2 between contour levels. All fields are vertically integrated throughout the entire atmosphere.

rivers are often associated with transient eddies. However, because the filaments occur at particular locations-for example, extending from warm oceanic regions such as the Pacific warm pool and the Gulf of Mexico into the storm tracks, or, in our simulations extending from south of the localized heating - they appear here as part of the stationary moisture flux term $\nabla \cdot\left(\overline{\mathbf{u}}^{\dagger} \bar{q}^{\dagger}\right)$. Similar LE stationary transport has been also associated with subtropical anticyclones (Shaw and Pauluis 2012). The moisture transported into midlatitudes by stationary eddies is then picked up by the transient eddies (Fig. 4b) and transported farther poleward, as indicated by the pattern of divergence and convergence of the transient LE flux in the extratropics (Fig. 4b).

To understand the role of the various components of the stationary eddy fluxes, we further split the total stationary eddy energy flux (Fig. 4) into the individual components [see (4)]. This includes the terms owing to interactions with the mean flow. The pure stationary eddy terms (Figs. 5a,b) are smaller in magnitude than the terms involving the zonal-mean flow (Figs. 5c-f), although the latter vanish in the zonal mean. Downstream of the surface heating region, both the DSE (Fig. 5a) and LE (Fig. 5b) components of the pure stationary eddy terms are similar in magnitude, but opposite in sign, to the transient energy flux terms (Figs. 4a,b). However, these terms do not completely compensate each other either locally or in the zonal mean. The main contribution to the stationary eddy DSE flux convergence $-\nabla \cdot\left(\overline{\mathbf{u}}^{\dagger} \bar{s}^{\dagger}\right)$ is from the advection of the stationary eddy DSE by the zonal-mean flow [third term on the righthand side of (4), Fig. 5c]. To leading order, this term is dominated by the zonal flow $\left\{\boldsymbol{\nabla} \cdot\left([\overline{\mathbf{u}}] \bar{s}^{*}\right) \approx[\bar{u}] \partial_{x} \bar{s}^{*}\right.$, where $\partial_{x}$ denotes the longitudinal derivative $\}$. Thus, the stationary eddy energy flux that acts against the transient downgradient flux (Fig. 4a), is caused primarily by zonal downstream energy fluxes, which extend approximately over half a Rossby wavelength (see section 5). The wave motion of the stationary eddies (creating warm and cold regions downstream) controls the length scale over which the downstream advection occurs, and therefore controls where the stationary energy flux maintains the mean equator-to-pole temperature gradient and where it reduces it.

The stationary LE flux convergence has contributions both from the pure stationary eddies (Fig. 5b), the zonalmean advection of the stationary fluctuations (Fig. 5d), and from the advection of the mean LE by the stationary eddies (Fig. 5f). The sum of these three contributions (Fig. 4d) is comparable in magnitude and opposite in sign to the transient LE flux convergence (Fig. 4b). The moisture source regions of the stationary and transient LE fluxes differ: the stationary fluxes originate primarily in low latitudes (Figs. 3b and 4d), whereas the transient fluxes originate in midlatitudes (Figs. $3 \mathrm{~b}$ and $4 \mathrm{~b}$ ). Comparing the relative contributions of DSE and LE to the total energy flux shows the importance of LE fluxes in maintaining the storm track. 

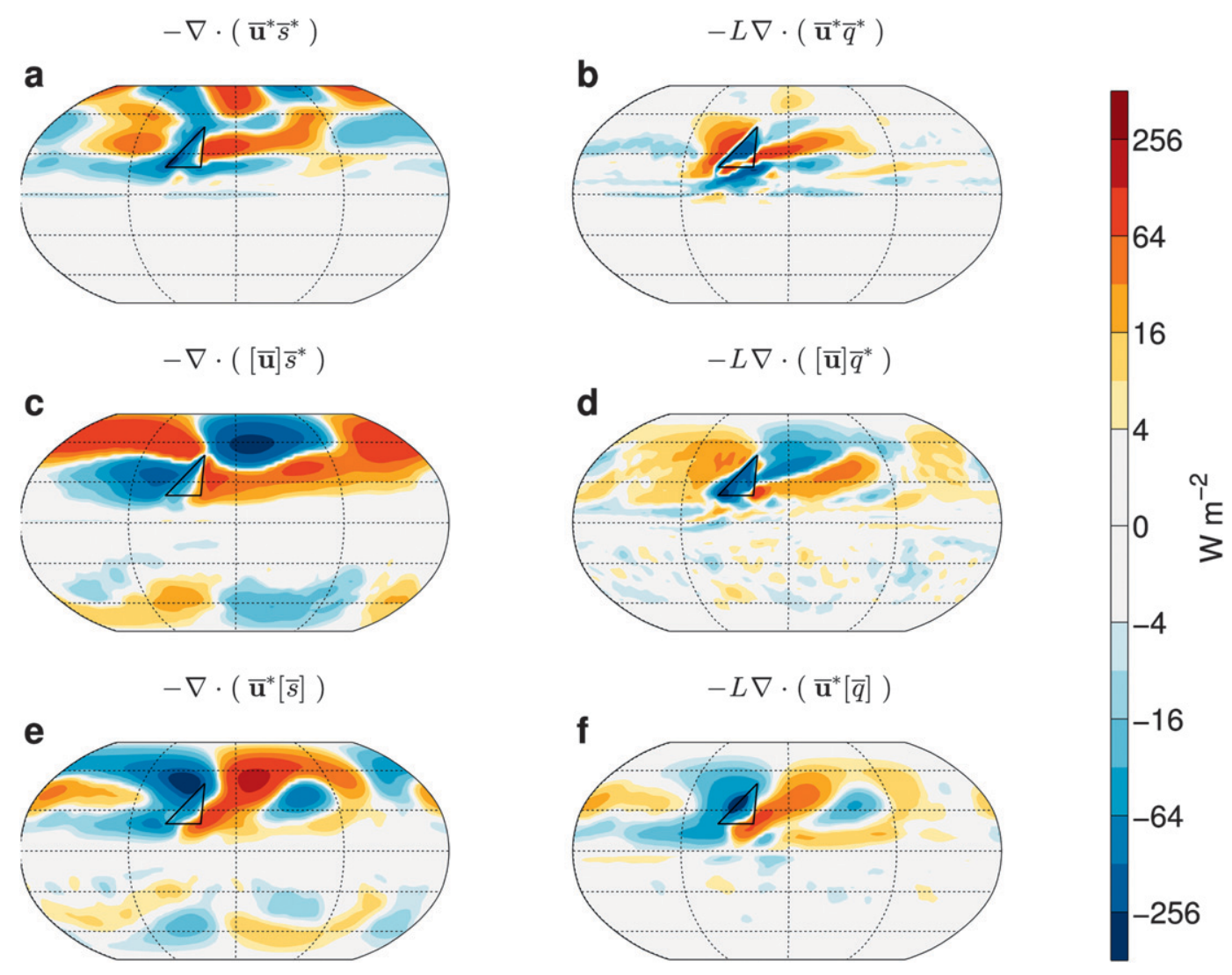

FIG. 5. Components of the stationary eddy energy flux convergence (vertically integrated). (a) Stationary eddy DSE flux convergence. (b) Stationary eddy LE flux convergence. (c) Advection of stationary eddy DSE by the mean flow. (d) Advection of stationary eddy LE by the mean flow. (e) Advection of the zonal-mean DSE by stationary eddies. (f) Advection of the zonal-mean LE by stationary eddies. The color scale is logarithmic, with factors of 2 between contour levels. All fields are vertically integrated throughout the entire atmosphere.

\section{Effect of rotation}

The map of vertically integrated EKE (Fig. 1a) shows that the Northern Hemisphere storm track weakens over land. Models with continents show a similar behavior (e.g., Chang 2009), often attributed to larger dissipation over the continents (e.g., Chang et al. 2002; Mak and Deng 2007), barotropic decay (Simmons and Hoskins 1980), or influences of orographic stationary waves (Sauliére et al. 2012). However, in our simulations even without any continents or varying surface friction, the storm track terminates over roughly the same length scale as in observations (Fig. 2a). In this section, we investigate the mechanisms controlling the termination of the storm track, using a series of simulations in which the rotation rate of the planet is varied. Using this approach has several advantages. First, since the storm-track length in the model is close to that observed on Earth, changing the rotation rate allows creating a larger scale separation between the length of the storm track and the circumference of the planet, thus giving more room to study the mechanisms controlling the storm-track length. Second, varying the rotation rate might allow separating the relative importance of the stationary wavelength scale and the transient eddy length scale. Stationary $(\omega=0)$ barotropic Rossby waves in Cartesian geometry and in a constant background flow have the dispersion relation

$$
0=\omega=\bar{u} k-\frac{\beta k}{K^{2}},
$$

where $\beta$ is the planetary vorticity gradient, $K^{2}=k^{2}+l^{2}$, and $k$ and $l$ are the zonal and meridional wavenumbers (Pedlosky 1987). Therefore, the stationary wavelength scale

$$
L_{s}=2 \pi(\bar{u} / \beta)^{1 / 2}
$$

varies as the inverse of the square root of the rotation rate if $\bar{u}$ variations can be neglected. By contrast, measures of the transient eddy length scale such as the deformation radius vary inversely with rotation rate if 

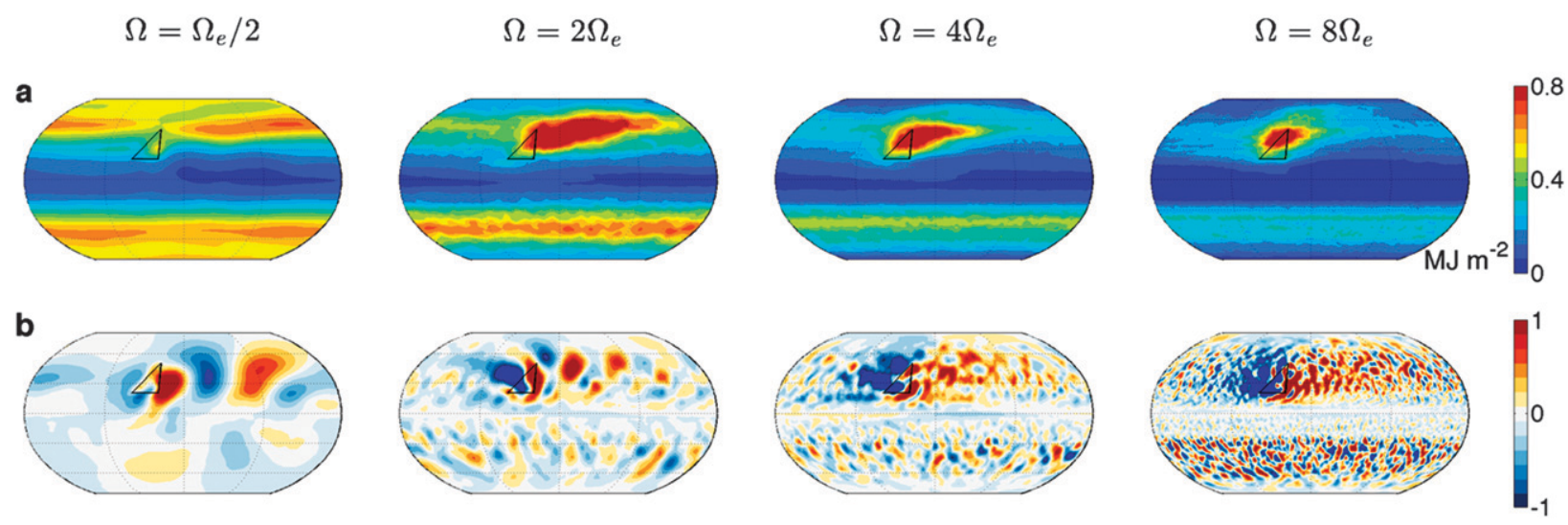

FIG. 6. (a) Vertically integrated tropospheric EKE for planetary rotation rates of $0.5 \Omega_{e}, 2 \Omega_{e}, 4 \Omega_{e}$, and $8 \Omega_{e}$. (b) Corresponding vertically integrated stationary meridional MSE flux $\left(\bar{v}^{\dagger} \bar{m}^{\dagger}\right)$. The units are nondimensional, with 1 corresponding to $1,0.6,0.25$, and $0.15 \mathrm{MW} \mathrm{m}^{-1}$ for planetary rotation rates of $0.5 \Omega_{e}, 2 \Omega_{e}, 4 \Omega_{e}$, and $8 \Omega_{e}$, respectively. The EKE in a similar simulation with planetary rotation rate $\Omega=\Omega_{e}$ shown in Fig. 2. Vertical integrals extend from $\sigma=0.3$ to the surface.

variations in the static stability can be neglected (Schneider and Walker 2006; Merlis and Schneider 2009). ${ }^{2}$

Comparing the transient EKE for four cases with the same thermal driving but rotation rates of $1 / 2,2,4$, and 8 times that of Earth $\Omega_{e}$ shows that the faster the rotation rate, the more zonally localized the storm track becomes (Fig. 6a). Locally in the storm-track region, EKE is enhanced; however, away from the localized heating, EKE is lower than in the reference Southern Hemisphere (Kaspi and Schneider 2011a). As the rotation rate increases, EKE in the zonally symmetric Southern Hemisphere decreases because the latitudinal region over which baroclinic instability occurs becomes more confined (Schneider and Walker 2008; O'Gorman and Schneider 2008c), thus decreasing the efficiency with which eddies convert mean available potential energy (MAPE) to EKE. We define MAPE using the Lorenz (1955) quadratic approximation for a dry ideal-gas atmosphere,

$$
\text { MAPE }=\frac{c_{p}}{2 p_{0}^{\kappa}} \int p^{\kappa} \Gamma(\bar{\theta}-\langle\bar{\theta}\rangle)^{2} d M
$$

where the angle brackets denote the isobaric global mean, $p_{0}=10^{5} \mathrm{~Pa}$ is a reference surface pressure, $\kappa=$ $R / c_{p}$ with $R$ being the gas constant of dry air, $M$ is total mass of the atmosphere, and $\Gamma=-(\kappa / p)(\partial \bar{\theta} / \partial p)^{-1}$ is an inverse measure of the dry static stability. By expanding

\footnotetext{
${ }^{2}$ Both for the stationary wavelength scale and the transient eddy length scale other factors beside the rotation rate (e.g., mean wind velocity and static stability) are important; however, we find that for the range of rotation rates we use (factor 48 variations), these factors vary on average by less than a factor of 4 , and therefore varying the rotation rate is a good method of varying these length scales.
}

the potential temperature variations (e.g., Schneider 1981; Schneider and Walker 2008), MAPE can be further approximated as

$$
\text { MAPE }=\frac{c_{p}}{24 p_{0}^{\kappa}} \int p^{\kappa} \Gamma\left(\partial_{y} \bar{\theta}\right)^{2} L_{z}^{2} d M,
$$

where $\partial_{y}$ is a meridional derivative and $L_{z}$ is a meridional length scale of the baroclinic region, which is controlled by the eddy length scale. Thus MAPE, and therefore baroclinicity, is controlled by the meridional temperature gradient and static stability. Peak EKE decreases with rotation rate because the width of the baroclinic region decreases with eddy length scales (Fig. 6a), even though the smaller eddy length scales also lead to a reduction in the poleward heat flux so that the equator-to-pole temperature gradient is enhanced (Schneider and Walker 2008). Figure 6b shows the corresponding stationary meridional flux $\left(\bar{v}^{\dagger} \bar{m}^{\dagger}\right)$, where $m=c_{p} T+g z+L q$ is the MSE. As expected from (6), the stationary eddy length scale decreases with increasing rotation rate.

To compare the downstream evolution of the storm track in the Northern Hemisphere with the reference Southern Hemisphere, Fig. 7 shows the EKE in each hemisphere averaged over the storm-track latitudes, defined as the region between latitude $30^{\circ}$ and where the EKE reduces to $80 \%$ of its Southern Hemisphere zonalmean maximum value. The two main features are that the EKE increases sharply immediately downstream of the localized heating in the Northern Hemisphere (red line), and that farther downstream the storm track selfdestructs so that the EKE in the Northern Hemisphere is smaller than that in the Southern Hemisphere (blue line). The downstream EKE in the Northern Hemisphere 

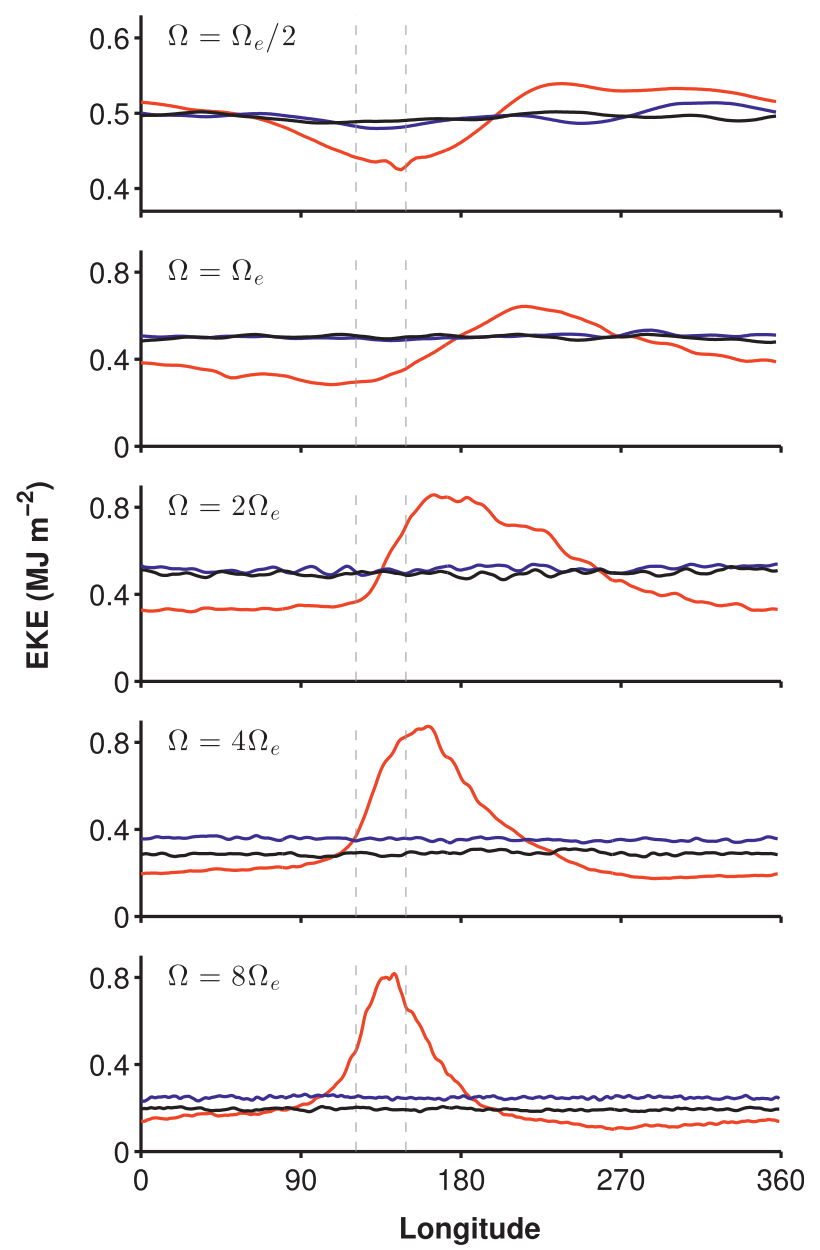

FIG. 7. EKE in the Northern Hemisphere (red) and Southern Hemisphere (blue) of the simulations with added heating, and in a control simulation without added heating (black), all vertically integrated between $\sigma=0.3$ and the surface, and averaged over the storm-track latitudes in each hemisphere. The different panels correspond to different planetary rotation rates (in multiples of Earth's rotation rate). Dashed-gray lines mark the region of the localized surface heating in the Northern Hemisphere.

is still weaker than in a simulation with no added heating at all (black line). This means that although the existence of a localized heating causes a local increase in EKE, it also leads to EKE self-destruction farther downstream, to values below those that would be obtained without the localized heating (Kaspi and Schneider 2011a). EKE is reduced downstream mainly because of stationary MSE fluxes, which we discuss in detail in section 5.

To get a consistent measure of the length of the storm track $L_{\mathrm{ST}}$, we define $L_{\mathrm{ST}}$ as the distance from the localized heating to the point downstream at which the Northern Hemisphere EKE is equal to the zonal-mean Southern Hemisphere EKE. For different rotation rates, the length of the storm track scales nearly as $\Omega^{-1 / 2}$

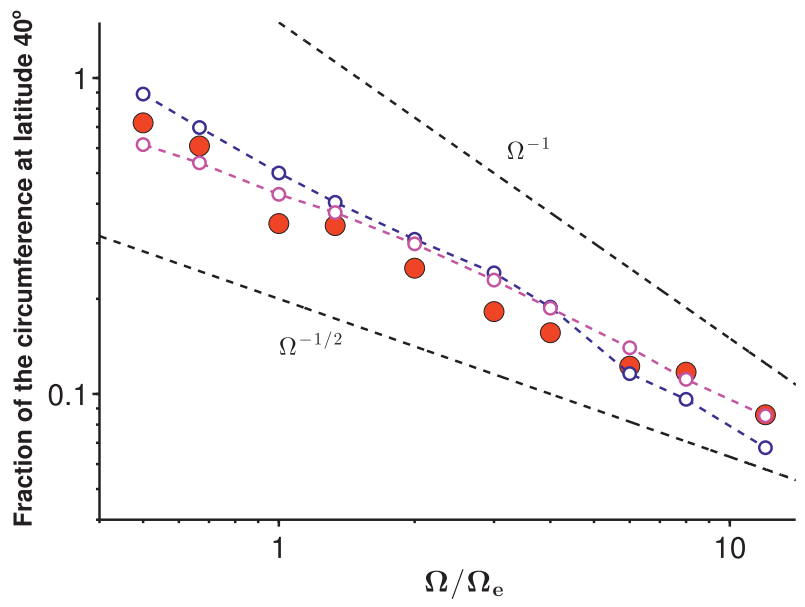

FIG. 8. Storm-track extent (red), defined as the longitudinal distance downstream between the localized heating and the latitude where the EKE of the Northern Hemisphere equals the Southern Hemisphere zonal-mean value averaged over the stormtrack latitudes. The storm-track extent is given as a fraction of Earth's circumference at latitude $40^{\circ}$ and is shown as a function of multiples of Earth's rotation rate. Blue dots are the stationary wavelength scale [see (6)] using the maximum zonal-mean $\bar{u}$ vertically averaged between 300 and $1000 \mathrm{hPa}$ (values range between 5 and $20 \mathrm{~m} \mathrm{~s}^{-2}$ ). Magenta dots are the energy-containing length scale for simulations with no localized heating [see (10)]. The thick dashed lines indicate power laws with exponents of -1 and $-1 / 2$.

(Fig. 8). ${ }^{3}$ It also scales fairly well with the length scale of the stationary wave [see (6)], using for $\bar{u}$ the maximum value of the vertically and zonally averaged zonal wind. (This value of $\bar{u}$ varies by roughly a factor of four over this range of rotation rates.)

In dry models, transient eddy length scales are similar to the Rossby deformation radius (Schneider and Walker 2008; Merlis and Schneider 2009). However, when including the effects of moisture, it is more difficult to represent the eddy length scale with simple scalings. To estimate the transient eddy length scale in the simulations without the localized heating, we use the energycontaining wavenumber $n_{e}$ defined by

$$
n_{e}\left(n_{e}+1\right)=\frac{\sum E_{n}}{\sum[n(n+1)]^{-1} E_{n}},
$$

where $n$ is the spherical wavenumber, and $E_{n}$ is the EKE spectrum omitting the zonal wavenumber 0 , thus omitting energy from the zonal-mean flow (Schneider and Walker 2008). We then define the energy-containing eddy length scale to be

\footnotetext{
${ }^{3}$ This relation breaks for slower rotation rates, for which the length of the storm track approaches the length of a latitude circle.
} 


$$
L_{e}=\frac{2 \pi a}{\left[n_{e}\left(n_{e}+1\right)\right]^{1 / 2}}
$$

where $a$ is Earth's radius. Overlaying this energycontaining length scale with the storm-track and stationary wave length scales shows that the energy-containing length scale is very similar to the stationary wave scale, showing close to the $\Omega^{-1 / 2}$ scaling rather than the $\Omega^{-1}$ scaling that would be expected from the deformation radius if the static stability were fixed (Fig. 8). This similarity in length scales arises because even in moist atmospheres, EKE appears to scale linearly with dry MAPE (O'Gorman and Schneider 2008a), implying there is a linear relation between the Rhines scale $L_{\beta}=2 \pi\left(u^{\prime} / \beta\right)^{1 / 2}$, with $\mathrm{rms}$ velocity scale $u^{\prime}$, and the stationary wavelength [see (6) $].{ }^{4}$ Thus, it is difficult to separate the stationary and transient length scales.

\section{Mechanisms linking stationary and transient eddies}

\section{a. Modification of temperature gradients}

Section 3 showed the separate contributions of dry and moist processes to the energy flux, where in both cases the energy flux is locally dominated by stationary eddies. In this section, instead of focusing on the individual contributions of dry and moist processes, we look at the combination of the two and focus on the MSE. This allows us to concentrate on how the total dynamic heating affects temperature gradients and baroclinicity. As in section 3, we begin with presenting zonally and vertically averaged fields.

The nonlinear interaction between the transient and stationary eddies can already be seen in the zonally symmetric fields (for which $\left[\bar{v}^{\dagger} \bar{m}^{\dagger}\right]=\left[\bar{v}^{*} \bar{m}^{*}\right]$ ). In Fig. 9, the zonally averaged poleward MSE flux $\overline{v m}$ is decomposed into the transient eddy component $\overline{v^{\prime} m^{\prime}}$ and the stationary eddy component $\bar{v}^{*} \bar{m}^{*}$. For the case with no zonal asymmetries (black lines), the stationary eddy component is zero. The total energy transport reaches 4-5 PW, similar to observations for the Southern Hemisphere during winter (Peixoto and Oort 1992). The transient eddy component has larger amplitude than the total in the extratropics because the mean-flow component is negative (because of the thermally

\footnotetext{
${ }^{4}$ A linear relation between MAPE and EKE implies that the Rossby radius $L_{R}$ and the Rhines scale $L_{\beta}$ (the expected energycontaining scale) are linearly related, $L_{\beta} \sim L_{R}$ (Schneider and Walker, 2006). Using this result, the scaling relations in Schneider and Walker (2006) and thermal wind balance then imply $u^{\prime} \sim \mathrm{EKE}^{1 / 2} \sim \bar{u}$.
}

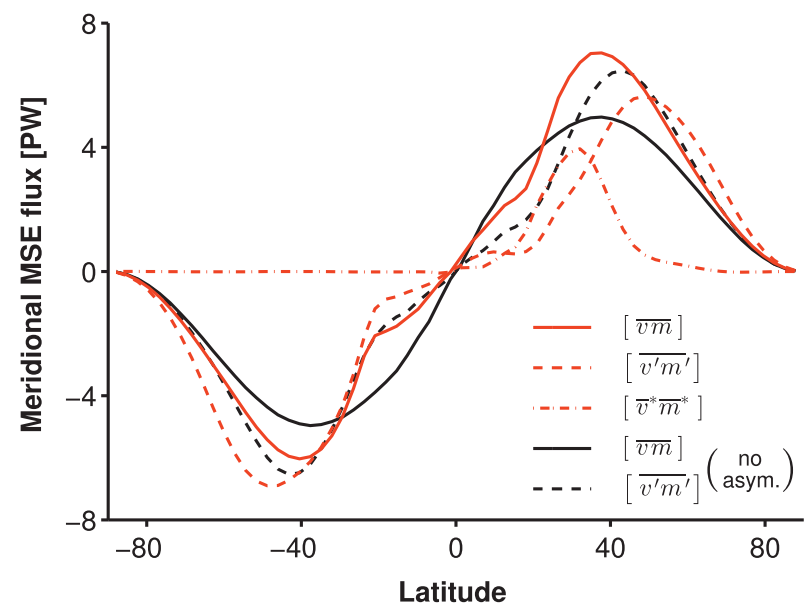

FIG. 9. Meridional MSE flux for the statistically zonally symmetric control climate without additional heating (black), and for the climate with a Northern Hemisphere zonally localized heat source (red). The solid lines indicate the total flux, dashed lines indicate the transient eddy flux, and dashed-dotted lines indicate the stationary eddy flux, which is nonzero only in the presence of stationary zonal asymmetries. All fields are zonally averaged and vertically integrated throughout the entire atmosphere.

indirect Ferrel cell; e.g., Vallis 2006). For the zonally asymmetric case with localized heating (red lines), in the Southern Hemisphere where the additional heating is spread out zonally symmetrically, both the total energy flux and the transient eddy energy flux are strengthened compared with the unperturbed case. However, in the Northern Hemisphere where the additional heating is zonally localized, the transient eddy energy fluxes are weakened in the zonal mean. The stationary eddy energy fluxes strengthen and overcompensate this weakening of the transients, so that the total poleward energy flux strengthens by about $20 \%$. This implies that transient eddies and stationary eddies in storm tracks interact nonlinearly (through their modification of the mean flow) and cannot be considered in isolation of each other. The MSE flux in our idealized model matches that estimated from observations (Oort and Peixóto 1983; Trenberth and Caron 2001). This increase in overall poleward energy flux as zonal asymmetries are introduced causes the reduction of meridional temperature gradients, resulting in reduced baroclinicity and the termination of the storm track downstream.

The meridional MSE fluxes showed the importance of the stationary eddies for the poleward energy transport. To understand the localization of storm tracks, we next look at the vertically integrated MSE flux convergence (Fig. 10). The individual (dry and moist) components of the MSE flux convergence (Fig. 4) showed that the stationary eddy DSE flux convergence locally dominates. Correspondingly dividing the MSE flux convergence 

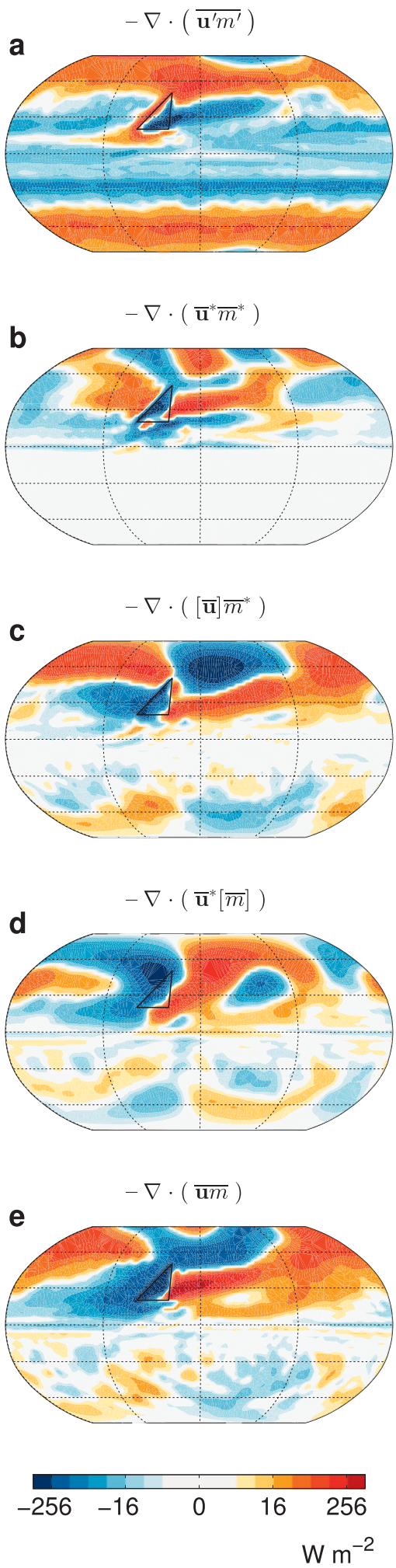

FIG. 10. Vertically integrated MSE flux convergence. (a) Transient eddies. (b) Stationary eddies. (c) Mean advection of stationary eddy MSE fluctuations. (d) Stationary advection of the zonal-mean MSE. (e) Total MSE flux convergence. The color scale is logarithmic, with factors of 2 between contour levels. All fields are vertically integrated throughout the entire atmosphere.
(Fig. 10e) into the individual components shows that it is likewise dominated by the stationary components (Figs. 10b-d), not by the transient component (Fig. 10a). Among the stationary eddy terms, the dominant term is the advection of the stationary eddy MSE by the zonal-mean wind (Fig. 10c), where the zonal component is dominant so that $\boldsymbol{\nabla} \cdot\left([\overline{\mathbf{u}}] \bar{m}^{*}\right) \approx[\bar{u}] \partial_{x} \bar{m}^{*}$. Thus, the mean zonal advection causes a strong divergence of MSE flux northeast of the localized heating (mainly because of downstream advection of cold air), which increases local temperature gradients downstream (Fig. 13a). This happens over about one-half Rossby wavelength downstream of the heating region since the temperature fluctuation of the wave, which is zonally advected, controls the pattern of dynamical heating and cooling. This is a main reason for the maintenance of the storm track, for which this process acts against the tendency of the transient MSE flux to reduce temperature gradients and therefore to weaken the storm track. A similar pattern is found for other rotation rates (Fig. 11).

To demonstrate how the stationary waves set the length of the storm track, Fig. 12 shows the meridional gradient of the MSE flux convergence, $-\partial_{y} \nabla \cdot\left(\overline{\mathbf{u}}^{\dagger} \bar{m}^{\dagger}\right)$, integrated vertically and over the storm-track latitudes (blue line). Negative values indicate flux that increases meridional temperature gradients, and positive values a flux that reduces temperature gradients. Over a range of rotation rates, this quantity anticorrelates with the storm-track EKE (red line), meaning that the enhancement of the storm track happens where the stationary eddies increase baroclinicity, thus giving a direct link between the stationary eddies and enhanced baroclinicity.

The localized heating also induces a surface cyclone to the east of it (Hoskins and Karoly 1981). This causes warm air advection from lower latitudes and enhanced dynamical heating east of the localized surface heating for half a stationary wavelength scale downstream of the localized heating (Fig. 10d). ${ }^{5}$ The combination of this dynamical heating by the stationary wave (Fig. 10d) and the advection of stationary eddy MSE fluctuation by the mean flow (Fig. 10c), which are both controlled by the stationary eddy length scale (Figs. 10c,d), determine the length scale over which the storm track terminates. The dynamical heating by the stationary wave enhances baroclinicity immediately downstream of the heating region and reduces it farther downstream. Over about the first one-half stationary wavelength scale, temperature

\footnotetext{
${ }^{5}$ The Icelandic and Aleutian lows on Earth are similar phenomena although they presumably arise not only because of local heating (over the Gulf Stream in the Atlantic and the Kuroshio in the Pacific), but also because of orography.
} 
$\Omega=\Omega_{e} / 2$

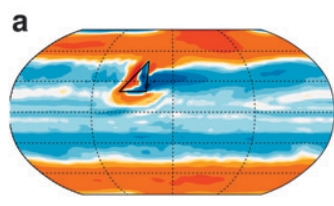

b

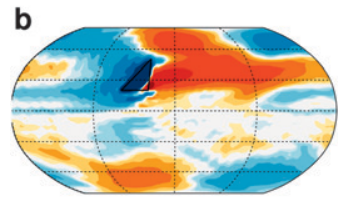

c

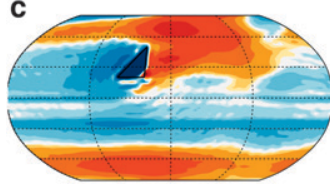

$\Omega=\Omega_{e}$

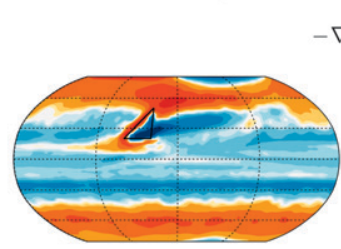

$\Omega=2 \Omega_{e}$

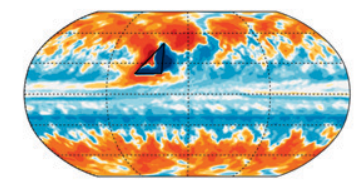

$-\nabla \cdot\left(\overline{\mathbf{u}}^{\dagger} \bar{m}^{\dagger}\right)$
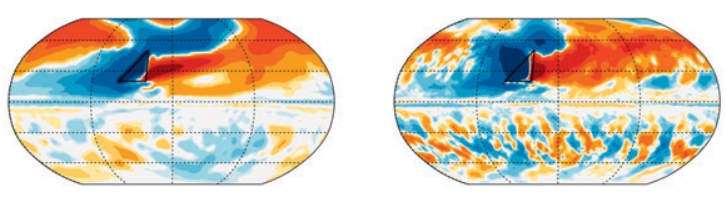

$-\nabla \cdot(\overline{\mathbf{u} m})$
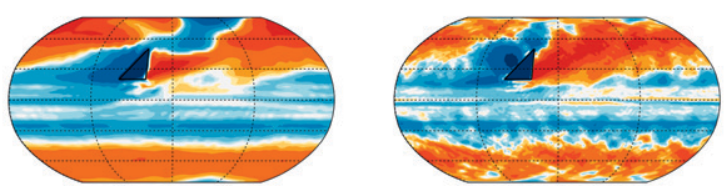

$\Omega=4 \Omega_{e}$

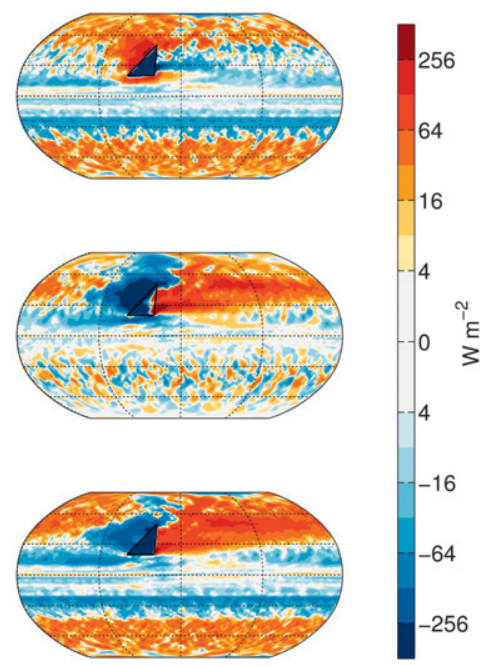

FIG. 11. Vertically integrated MSE flux convergence. (a) Transient eddies. (b) Stationary eddies. (c) Total $-\nabla \cdot(\overline{\mathbf{u}} m)$, for four different rotation rates $\left(\Omega_{e} / 2,2 \Omega_{e}, 4 \Omega_{e}, 8 \Omega_{e}\right)$. The color scale is logarithmic, with factors of 2 between contour levels. All fields are vertically integrated throughout the entire atmosphere.

gradients and thus the baroclinicity are enhanced because of dynamical heating to the south and cooling to the north of the storm track (see how the combination of Figs. 10c and 10d leads to Fig. 10e); farther downstream, baroclinicity is reduced because the stationary components of the poleward heat flux contribute to reduction of meridional temperature gradients (positive value of the net effect of the stationary components downstream of the storm track in Fig. 12).

The difference in meridional temperature gradients between the Northern Hemisphere and the Southern Hemisphere zonal mean allows us to quantify the effect of the localized heating on the meridional temperature gradients. Figure 13a shows that beyond the region of local increase in the Northern Hemisphere downstream of the localized heating, the temperature gradient is generally smaller everywhere else around the latitudes of the perturbation. The addition of approximately $1 \mathrm{PW}$ of poleward energy transport (Fig. 9) results in a decrease in vertically averaged temperature gradients on the order of $3 \times 10^{-3} \mathrm{~K} \mathrm{~km}^{-1}$ in midlatitudes (Fig. 13a). This decrease in temperature gradients appears to be a key reason for the decrease in baroclinic conversion downstream, which results in the decrease in EKE (Figs. 6 and 7) and the termination of the storm track. For all rotation rates in Fig. 8, there is an approximately 1-PW increase in poleward MSE flux compared to the zonally symmetric Southern Hemisphere, and approximately 2-PW increase compared to a case with no added heating (Kaspi and Schneider 2011a). Similarly, Earth's Northern Hemisphere has a poleward MSE flux that is about 2 PW larger than that of the Southern Hemisphere, where the contribution of stationary eddies is smaller (Oort and Peixóto 1983).

In summary, we have shown that, in the zonal mean, the existence of localized heating and the stationary eddies it generates cause an increase in the zonal-mean poleward MSE flux and therefore a reduction of zonalmean temperature gradients, resulting in less baroclinicity and less EKE. Over about half a stationary wavelength downstream of the localized heating, however, baroclinicity is increased mainly by downstream advection of MSE by stationary eddies (Figs. 10 and 12). This opposes the tendency of the transient eddies to decrease baroclinicity. Hoskins and Valdes (1990) pointed to the possibility that latent heat release acts in some way to fuel the storm track and oppose the destruction of mean gradients by the transient eddies. In our simulations, stationary eddy fluxes of DSE and LE, induced by the localized heating, lead to energy fluxes that enhance baroclinicity immediately downstream of the heating and thereby oppose the destruction of mean gradients by the transient eddies.

\section{b. Modification of static stability}

MAPE and baroclinic generation are controlled not only by the meridional temperature gradients, but also by the static stability [see (8)]. Therefore, to quantify the baroclinicity in the storm-track entrance and exit regions, the effect of the eddies on the static stability should also be considered. Recent studies have shown that the static 

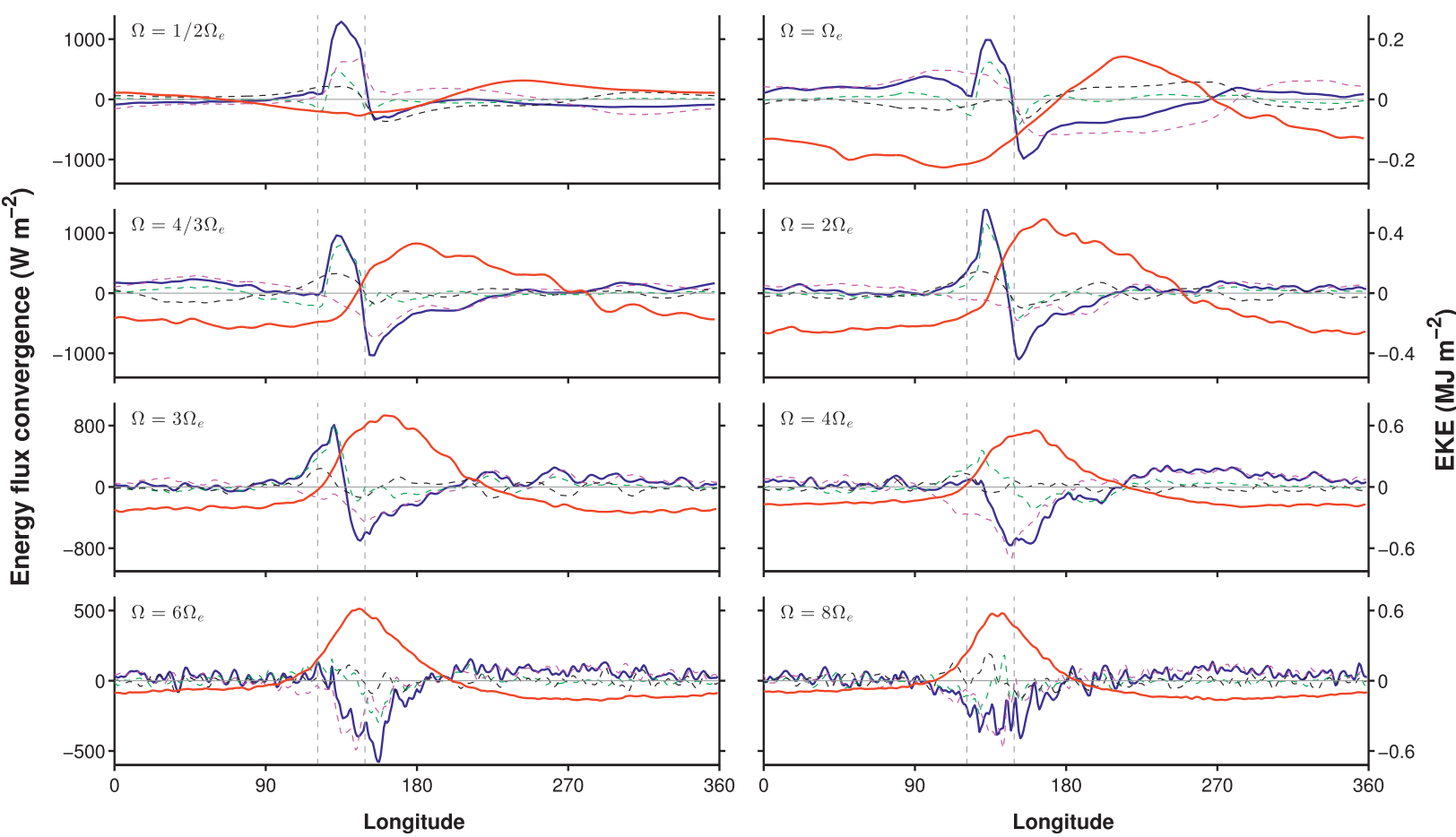

FIG. 12. Meridional gradient of the stationary eddy MSE flux convergence (e.g., Fig. 11b) integrated vertically and over storm-track latitudes, $-\int_{\phi_{2}}^{\phi_{1}}(\partial / \partial \phi)\left\{\boldsymbol{\nabla} \cdot\left(\overline{\mathbf{u}}^{\dagger} \bar{m}^{\dagger}\right)\right\} d \phi$ (blue). Here, $\phi_{1}=30^{\circ} \mathrm{N}$ and $\phi_{2}$ is the northern edge of the storm track, defined as the latitude where the EKE decreases to $80 \%$ of the maximum Southern Hemisphere zonal-mean EKE. (For rotation rates $1 / 2 \Omega_{e}, \Omega_{e}, 4 / 3 \Omega_{e}, 2 \Omega_{e}, 3 \Omega_{e}, 4 \Omega_{e}$, $6 \Omega_{e}$, and $8 \Omega_{e}, \phi_{2}$ is $67^{\circ}, 61^{\circ}, 59^{\circ}, 56^{\circ}, 52^{\circ}, 49^{\circ}, 45^{\circ}$, and $43^{\circ} \mathrm{N}$, respectively.) For comparison, the EKE difference between the Northern and Southern Hemispheres integrated over the same latitudes is shown in red (right axis scale). The individual components of the gradients of the stationary eddy MSE convergence are the dashed lines: advection of the stationary eddy MSE perturbation by the mean flow $-\int_{\phi_{2}}^{\phi_{1}}(\partial / \partial \phi)\left([\mathbf{u}] \cdot \nabla \bar{m}^{*}\right) d \phi$ (magenta); zonal-mean stationary eddies $-\int_{\phi_{2}}^{\phi_{1}}(\partial / \partial \phi)\left\{\boldsymbol{\nabla} \cdot\left(\overline{\mathbf{u}}^{*} \bar{m}^{*}\right)\right\} d \phi$ (green); advection of the mean MSE gradient by stationary eddies $-\int_{\phi_{2}}^{\phi_{1}}(\partial / \partial \phi)\left\{\bar{v}^{*}(1 / a)(\partial / \partial \phi)[\bar{m}]\right\} d \phi$ (black). Negative values indicate a tendency to increase meridional temperature gradients. The dashed-gray lines indicate the longitudes of the Northern Hemisphere localized heating. For rotation rates slower than $\Omega / 2$, the length of the storm track approaches the length of a latitude circle. Note that downstream positive values that indicate reduction of temperature gradients appear small because of the vertical axis but are actually of order $100 \mathrm{~W} \mathrm{~m}^{-2}$.

stability may be important for controlling the latitudinal position of the storm track ( $\mathrm{Lu}$ et al. 2010) and its intensity under climate change (O'Gorman 2010). The dry static stability difference between the Northern Hemisphere and the Southern Hemisphere zonal mean in our reference simulation shows that in the storm track and particularly upstream of the entrance region, there are regions of enhanced dry static stability (Fig. 13b). ${ }^{6}$ High static stability results in reduced baroclinicity and therefore, in combination with the reduced temperature gradients downstream, results in the localization of the storm track. To understand the mechanisms leading to the increase in static stability, we look separately at the

\footnotetext{
${ }^{6}$ We use the dry static stability, which we find for these cases not to differ much in the extratropics from moist measures such as that of O'Gorman (2011).
}

regions upstream and downstream of the localized heating.

Upstream, there is advection of cold polar air near the surface, resulting from the surface cyclone created in response to surface heating (Hoskins and Karoly 1981). The longitudinal length scale of this region is controlled by the stationary Rossby wave plume induced by the localized heating (Rhines 2002; Kaspi and Schneider 2011b). This cold near-surface air decreases the lapse rate near the surface and increases the static stability. The region of increased static stability upstream correlates with the region of cold temperature anomalies (Kaspi and Schneider 2011b). This local increase in static stability can contribute to the reduction in storm-track activity upstream of the storm-track entrance regions (Fig. 1a). Similar cold regions with high static stability near the surface (and even inversions) are found near the eastern continental boundaries during winter (Lee and Mak 1994). However, the high-rotation-rate cases show that 

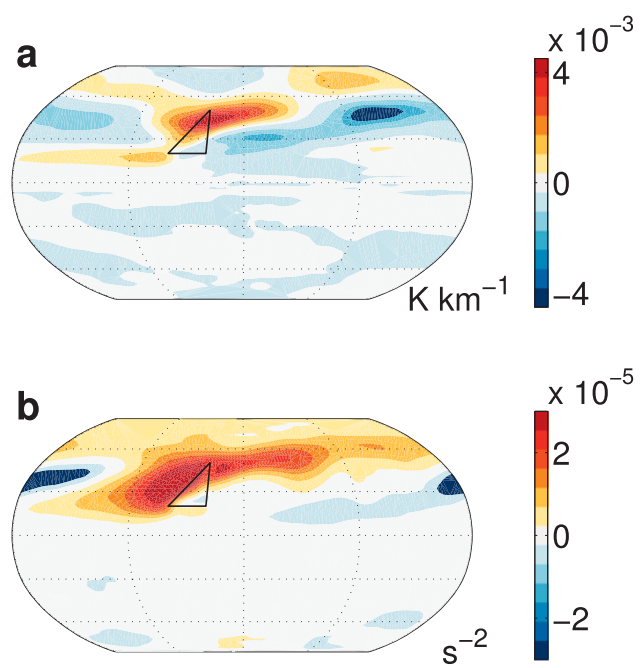

FIG. 13. (a) Difference in absolute value of vertically averaged meridional temperature gradients between the Northern Hemisphere and the Southern Hemisphere zonal mean. (b) Vertically averaged dry static stability $\left\{N^{2}=(g / \bar{\theta})(\partial \bar{\theta} / \partial z)\right\}$ difference between the Northern Hemisphere and the Southern Hemisphere zonal mean. The static stability is vertically averaged between $\sigma=$ 0.3 and 0.9 , omitting the layer adjacent to the surface to avoid numerical problems caused by the low static stability there.

there is a longitudinal separation between the upstream regions of enhanced static stability and the downstream termination of the storm track. Therefore, this effect is not significant for the termination of the storm track.

Downstream of the localized heating, the increase in static stability arises mainly because of LE release. The stationary moisture fluxes bring streams of moisture from the tropics to the extratropics (Fig. 4d), and this moisture is then picked up by the transient eddies and
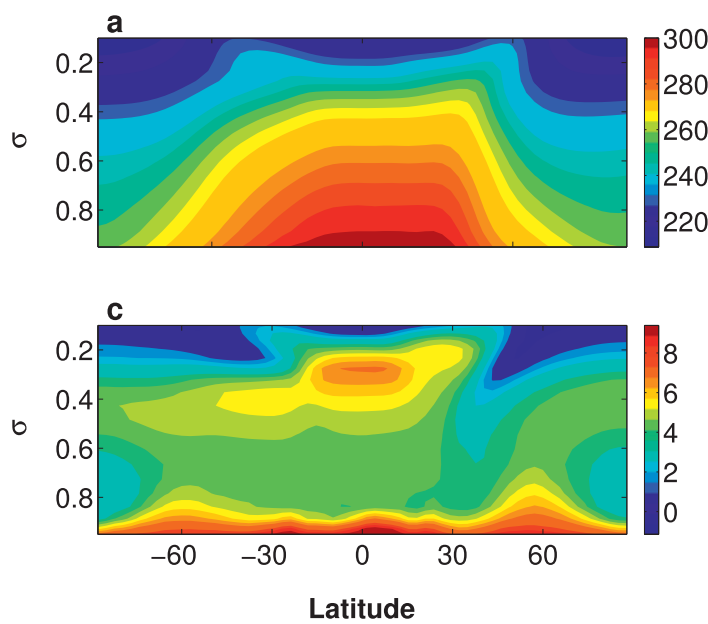

FIG. 14. (a) Temperature (K). (b) Equivalent potential temperature (K). (c) Negative of vertical temperature gradient, $-\partial_{z} T\left(\mathrm{~K} \mathrm{~km}^{-1}\right)$. (d) Static stability $\left(\mathrm{s}^{-2}\right)$. All are zonally averaged over $60^{\circ}$ longitude downstream of the localized heating region. carried farther northward. The air cools adiabatically as it moves upward and poleward (Fig. 14b), resulting in condensation and latent heat release aloft in the midtroposphere (Fig. 15b). This heating reduces the lapse rate (Fig. 14c) and increases the static stability (Fig. $14 \mathrm{~d})$, resulting in reduced baroclinicity (Schneider and O'Gorman 2008). As seen horizontally in Fig. 5c and vertically in Fig. 15e, the zonal-mean advection of the stationary eddies carries this midlevel heating farther downstream. This results in the net dynamic cooling seen in Fig. 15e, and it increases the static stability farther downstream, beyond the region of the storm track (Fig. 13b). This is an additional mechanism by which the stationary circulation is important in shaping the storm tracks. The main contributors in midlatitudes to the reduced vertical temperature gradients and increased static stability are the transient fluxes, with LE flux convergence dominating DSE convergence (cf. Figs. 15a,b). We find that the downstream increase in static stability reduces MAPE by an additional $20 \%$ beyond the value of MAPE owing only to reduced meridional temperature gradients, which reduce MAPE by $40 \%$ compared with the Southern Hemisphere. Therefore, modification of meridional temperature gradients through stationary eddies is dominant over modifications of static stability in controlling local baroclinicity in our simulations.

\section{Conclusions}

A common theme that arises in the storm-track literature is whether the storm track is self-maintained: can the transient eddies maintain themselves in forming the storm track, or are they controlled by other sources
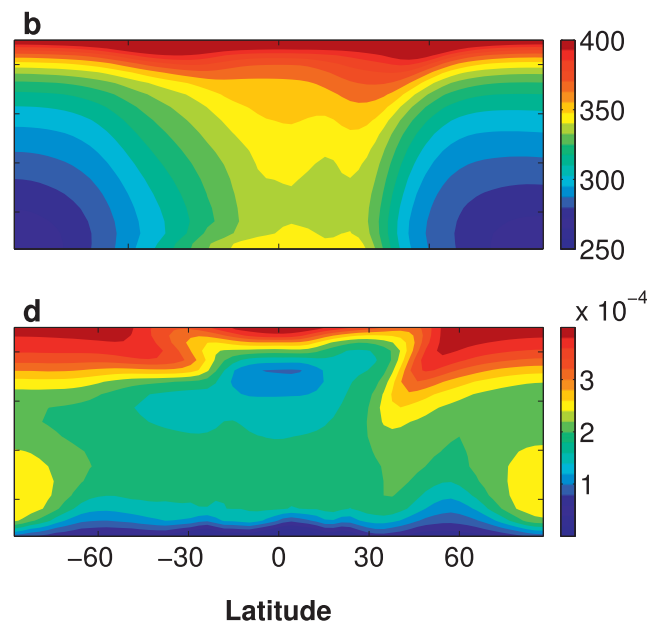

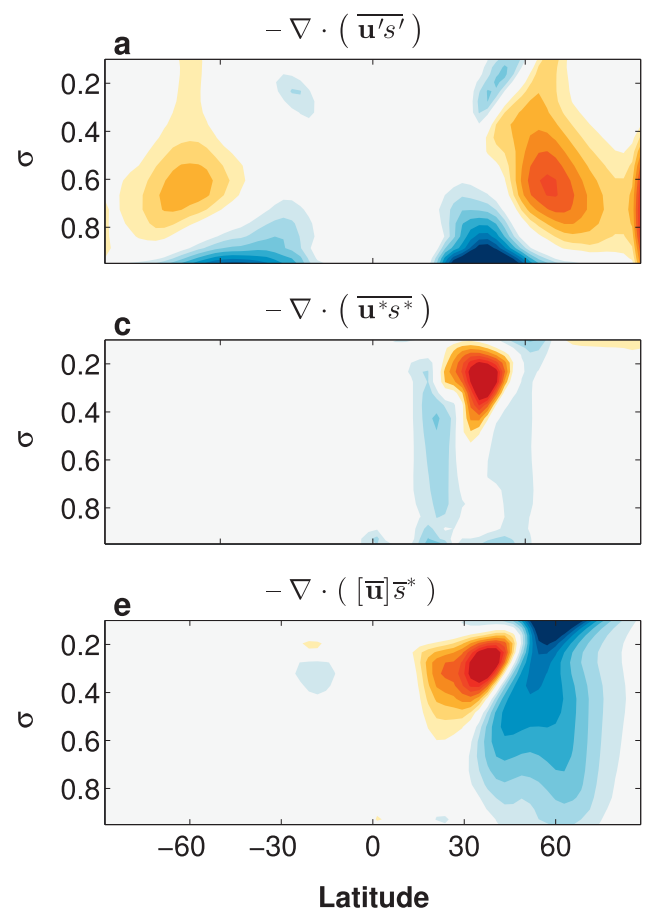

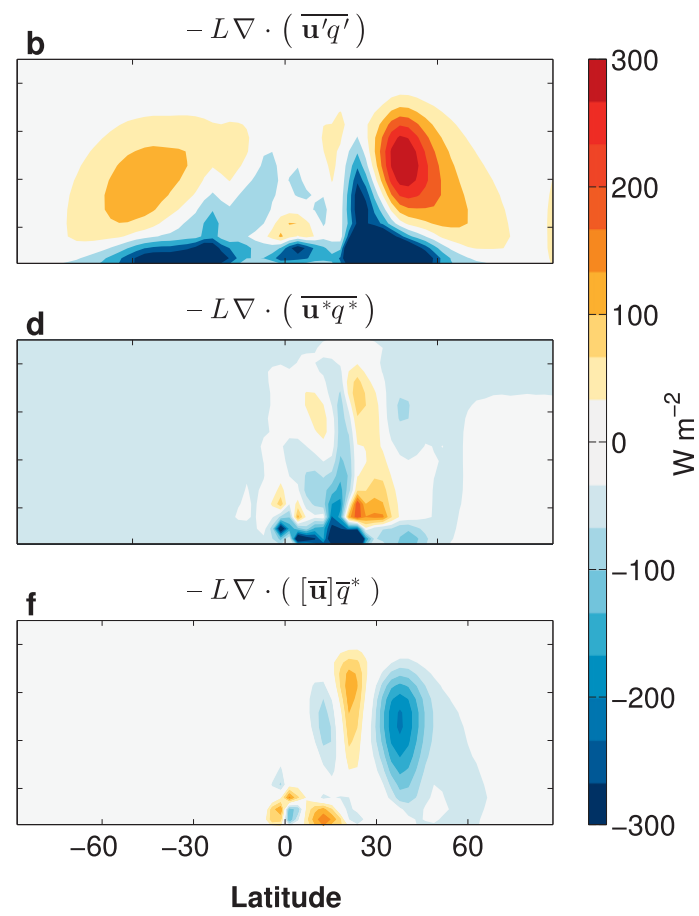

Latitude

FIG. 15. Components of the energy flux convergence. (a) Transient eddy DSE flux convergence. (b) Transient eddy LE flux convergence. (c) Stationary eddy DSE flux convergence. (d) Stationary eddy LE flux convergence. (e) Advection of stationary eddy DSE by the zonal-mean wind. (f) Advection of stationary LE by the zonal-mean wind. All fields are zonally averaged over a region $60^{\circ}$ in longitude downstream of the eastern edge of the localized heating.

such as diabatic heating, surface damping, or stationary waves? Here we have shown that a zonal asymmetry that leads to storm-track formation also causes stationary eddies, which both maintain the storm track within about half a Rossby wavelength of the storm-track entrance region and terminate it farther downstream. Using an aquaplanet moist GCM with localized surface heating, we have shown that the stationary eddies (including interactions with the zonal-mean flow) are locally more important to the energy budget than the transient eddies. The stationary eddy energy flux convergences induced by the zonal asymmetries are large in the storm-track region, where they increase temperature gradients, counteracting the tendency of the transient eddies to reduce temperature gradients. Such local dominance of stationary over transient eddies is also found in AGCM experiments with a zonally varying but fixed SST (Inatsu et al. 2003). Farther downstream, stationary eddy energy fluxes reduce the temperature gradients. This results in regions downstream of the storm track where the EKE is even lower than it would have been without zonal asymmetries and storm tracks, similar to regions of weak eddy activity observed over continents. Therefore, even without continents, the storm track can be well localized, with length scales similar to those observed on Earth.
Varying the rotation rate of the planet allows us to study the generation of storm tracks systematically. We have shown that as the rotation rate is increased, the length of the storm track decreases. It scales with the length of the stationary eddies, pointing to the role of stationary eddies in terminating the storm track. This occurs both because of enhanced poleward MSE transport downstream of the storm track, which reduces temperature gradients and therefore baroclinicity, and because of increased static stability resulting from LE release at midlevels, which also reduces baroclinicity. For a climate similar to that of present-day Earth, the reduction in temperature gradients is the dominant of these two processes, though caution should be taken in interpreting these results quantitatively because of the simplicity of the idealized model and the particular experimental design. In addition, the latitudinal location of the region of localized heating relative to the latitudinal location of the mean jet can play an important role in how the stationary and transient eddies interact (e.g., Peng and Whitaker 1999; Inatsu et al. 2003), and, for example, may lead to the differences between the characters of the Atlantic and Pacific storm tracks (Chang et al. 2002).

The existence of zonal asymmetries leads to a reduction in transient poleward energy fluxes. Stationary 
energy fluxes not only compensate this reduction but overcompensate it, so that the zonal-mean poleward energy transport is increased, resulting in reduced temperature gradients. Local convergences of LE fluxes and DSE fluxes in the storm-track region are of similar magnitude, pointing to the importance of moist processes in the dynamics of storm tracks.

Acknowledgments. This research has been supported by the NOAA Climate and Global Change Postdoctoral Fellowship administered by the University Corporation for Atmospheric Research, by a David and Lucile Packard Fellowship, by NSF Grant AGS-1019211, and by a Marie Curie Career Integration Grant CIG-304202. We thank Simona Bordoni, Xavier Levine, Tim Merlis, and Adam Sobel for very helpful discussions during the preparation of this manuscript. The simulations were performed on Caltech's Division of Geological and Planetary Sciences Dell cluster.

\section{REFERENCES}

Blackmon, M. L., 1976: A climatological spectral study of the $500-\mathrm{mb}$ geopotential height of the Northern Hemisphere. J. Atmos. Sci., 33, 1607-1623.

Branstator, G., 1995: Organization of storm-track anomalies by recurring low-frequency circulation anomalies. J. Atmos. Sci., 52, 207-226.

Brayshaw, D. J., B. Hoskins, and M. Blackburn, 2008: The stormtrack response to idealized SST perturbations in an aquaplanet GCM. J. Atmos. Sci., 65, 2842-2860.

- - $—$, and $—$ 2009: The basic ingredients of the North Atlantic storm track. Part I: Land-sea contrast and orography. J. Atmos. Sci., 66, 2539-2558.

,-- , and,- 2011 : The basic ingredients of the North Atlantic storm track. Part II: Sea surface temperatures. J. Atmos. Sci., 68, 1784-1805.

Broccoli, A. J., and S. Manabe, 1992: The effects of orography on midlatitude Northern Hemisphere dry climates. J. Climate, 5 , 1181-1201.

Chang, E. K. M., 1993: Downstream development of baroclinic waves as inferred from regression analysis. J. Atmos. Sci., 50, 2038-2053.

- 2001: GCM and observational diagnoses of the seasonal and interannual variations of the Pacific storm track during the cool season. J. Atmos. Sci., 58, 1784-1800.

_- 2009: Diabatic and orographic forcing of northern winter stationary waves and storm tracks. J. Climate, 22, 670-688.

—, and I. Orlanski, 1993: On the dynamics of a storm track. J. Atmos. Sci., 50, 999-1015.

— S. Lee, and K. L. Swanson, 2002: Storm-track dynamics. J. Climate, 15, 2163-2183.

Frierson, D. M. W., 2007: The dynamics of idealized convection schemes and their effect on the zonally averaged tropical circulation. J. Atmos. Sci., 64, 1959-1976.

—, I. M. Held, and P. Zurita-Gotor, 2006: A gray-radiation aquaplanet moist GCM. Part I: Static stability and eddy scale. J. Atmos. Sci., 63, 2548-2566.

Frisius, T., F. Lunkeit, K. Fraedrich, and I. N. James, 1998: Stormtrack organization and variability in a simplified atmospheric global circulation model. Quart. J. Roy. Meteor. Soc., 124, 1019-1043.

GFDL, 2004: The new GFDL global atmosphere and land model AM2-LM2: Evaluation with prescribed SST simulations. J. Climate, 17, 4641-4673.

Harnik, N., and E. K. M. Chang, 2004: The effects of variations in jet width on the growth of baroclinic waves: Implications for midwinter Pacific storm-track variability. J. Atmos. Sci., 61, 23-40.

Held, I. M., M. Ting, and H. Wang, 2002: Northern winter stationary waves: Theory and modeling. J. Climate, 15, 21252144.

Hoskins, B. J., and D. J. Karoly, 1981: The steady linear response of a spherical atmosphere to thermal and orographic forcing. J. Atmos. Sci., 38, 1179-1196.

— J. Atmos. Sci., 47, 1854-1864.

Inatsu, M., H. Mukougawa, and S.-P. Xie, 2002: Stationary eddy response to surface boundary forcing: Idealized GCM experiments. J. Atmos. Sci., 59, 1898-1915.

,-- , and,- 2003 : Atmospheric response to zonal variations in midlatitude SST: Transient and stationary eddies and their feedback. J. Climate, 16, 3314-3329.

Kaspi, Y., and T. Schneider, 2011a: Downstream self-destruction of storm tracks. J. Atmos. Sci., 68, 2459-2464.

$\longrightarrow$, and _ 2011b: Winter cold of eastern continental boundaries induced by warm ocean waters. Nature, 471, 621-624.

Kushnir, Y., W. A. Robinson, I. Bladé, N. M. J. Hall, S. Peng, and R. Sutton, 2002: Atmospheric GCM response to extratropical SST anomalies: Synthesis and evaluation. J. Climate, 15, 22332256.

Lau, N. C., 1979a: The structure and energetics of transient disturbances in the Northern Hemisphere wintertime circulation. J. Atmos. Sci., 36, 982-995.

_ 1979b: The observed structure of tropospheric stationary waves and the local balances of vorticity and heat. J. Atmos. Sci., 36, 996-1016.

Lee, S., 1995: Localized storm tracks in the absence of local instability. J. Atmos. Sci., 52, 977-989.

_- and I. M. Held, 1993: Baroclinic wave packets in models and observations. J. Atmos. Sci., 50, 1413-1428.

Lee, W.-J., and M. Mak, 1994: Observed variability in the largescale static stability. J. Atmos. Sci., 51, 2137-2144.

Lorenz, E. N., 1955: Available potential energy and the maintenance of the general circulation. Tellus, 7, 157-167.

Lu, J., G. Chen, and D. M. W. Frierson, 2010: The position of the midlatitude storm track and eddy-driven westerlies in aquaplanet AGCMs. J. Atmos. Sci., 67, 3984-4000.

Mak, M., and Y. Deng, 2007: Diagnostic and dynamical analyses of two outstanding aspects of storm tracks. Dyn. Atmos. Oceans, 43, 80-99.

Manabe, S., and T. B. Terpstra, 1974: The effects of mountains on the general circulation of the atmosphere as identified by numerical experiments. J. Atmos. Sci., 31, 3-42.

Merlis, T. M., and T. Schneider, 2009: Scales of linear baroclinic instability and macroturbulence in dry atmospheres. J. Atmos. Sci., 66, 1821-1833.

Newell, R. E., N. E. Newell, and C. Scott, 1992: Tropospheric rivers?-A pilot study. Geophys. Res. Lett., 19, 2401-2404.

Newman, M., G. N. Kiladis, K. M. Weickmann, F. M. Ralph, and P. D. Sardeshmukh, 2012: Relative contributions of synoptic and low-frequency eddies to time-mean atmospheric moisture transport, including the role of atmospheric rivers. J. Climate, 25, 7341-7361. 
O'Gorman, P. A., 2010: Understanding the varied response of the extratropical storm tracks to climate change. Proc. Natl. Acad. Sci. USA, 107, 19176-19180.

_ 2011: The effective static stability experienced by eddies in a moist atmosphere. J. Atmos. Sci., 68, 75-90.

—, and T. Schneider, 2008a: Energy in midlatitude transient eddies in idealized simulations of changed climates. J. Climate, 21, 5797-5806.

_ climates simulated with an idealized GCM. J. Climate, 21, 3815-3832.

— and _ 2008c: Weather-layer dynamics of baroclinic eddies and multiple jets in an idealized general circulation model. J. Atmos. Sci., 65, 524-535.

Oort, A. H., and J. P. Peixóto, 1983: Global angular momentum and energy balance requirements from observations. $A d v$. Geophys., 25, 355-490.

Orlanski, I., 1998: Poleward deflection of storm tracks. J. Atmos. Sci., 55, 2577-2602.

_ , and J. Katzfey, 1991: The life cycle of a cyclone wave in the Southern Hemisphere. Part I: Eddy energy budget. J. Atmos. Sci., 48, 1972-1998.

Park, H., J. C. H. Chiang, and S. Son, 2010: The role of the central Asian mountains on the midwinter suppression of North $\mathrm{Pa}$ cific storminess. J. Atmos. Sci., 67, 3706-3720.

Pedlosky, J., 1987: Geophysical Fluid Dynamics. Spinger, 742 pp.

Peixoto, J. P., and A. H. Oort, 1992: Physics of Climate. American Institute of Physics, $520 \mathrm{pp}$.

Peng, S., and J. S. Whitaker, 1999: Mechanisms determining the atmospheric response to midlatitude SST anomalies. J. Climate, 12, 1393-1408.

Rhines, P. B., 2002: Rossby waves. Encyclopedia of Atmospheric Sciences. J. Holton, J. Curry, and J. Pyle, Eds., Academic Press, 1923-1939.

Sauliére, J., D. J. Brayshaw, B. Hoskins, and M. Blackburn, 2012: Further investigation of the impact of idealized continents and SST distributions on the Northern Hemisphere storm tracks. J. Atmos. Sci., 69, 840-856.
Schneider, E. K., 1981: On the amplitudes reached by baroclinically unstable disturbances. J. Atmos. Sci., 38, 2142-2149.

Schneider, T., and C. C. Walker, 2006: Self-organization of atmospheric macroturbulence into critical states of weak nonlinear eddy-eddy interactions. J. Atmos. Sci., 63, 1569-1586.

— and P. A. O'Gorman, 2008: Moist convection and the thermal stratification of the extratropical troposphere. J. Atmos. Sci., $\mathbf{6 5}, 3571-3583$.

— macroturbulence in dry atmospheres. J. Atmos. Sci., 65, 21532173.

—_ P. A. O'Gorman, and X. J. Levine, 2010: Water vapor and the dynamics of climate change. Rev. Geophys., 48, RG3001.

Seager, R., D. S. Battisti, J. Yin, N. Gordon, N. Naik, A. C. Clement, and M. A. Cane, 2002: Is the Gulf Stream responsible for Europe's mild winters? Quart. J. Roy. Meteor. Soc., 128, 2563 2586

Shaw, T. A., and O. Pauluis, 2012: Tropical and subtropical meridional latent heat transports by disturbances to the zonal mean and their role in the general circulation. J. Atmos. Sci., 69, 1872-1889.

Simmons, A. J., and B. J. Hoskins, 1980: Barotropic influences on the growth and decay of nonlinear baroclinic waves. J. Atmos. Sci., 37, 1679-1684.

Son, S.-W., M. Ting, and L. M. Polvani, 2009: The effect of topography on storm-track intensity in a relatively simple general circulation model. J. Atmos. Sci., 66, 393-411.

Trenberth, K. E., and J. M. Caron, 2001: Estimates of meridional atmosphere and ocean heat transports. J. Climate, 14, 34333443.

Vallis, G. K., 2006: Atmospheric and Oceanic Fluid Dynamics. Cambridge University Press, 770 pp.

Zhu, Y., and R. E. Newell, 1998: A proposed algorithm for moisture fluxes from atmospheric rivers. Mon. Wea. Rev., 126, 725-735.

Zurita-Gotor, P., and E. K. M. Chang, 2005: The impact of zonal propagation and seeding on the eddy-mean flow equilibrium of a zonally varying two-layer model. J. Atmos. Sci., 62, 22612273. 